\title{
ASPECTOS FORMALES Y TÓPICOS DE LOS CONTRATOS PRIVADOS SICILIANOS
}

\author{
Dedicado a Jürgen Untermann ${ }^{1}$
}

\begin{abstract}
Since F. Pringsheim (1950) the reading of the Greek law of sale has changed. He interpreted the Greek sale as a cash-contract, where the formalism of the transactions and the difference - though not legal - between possession and ownership are the main elements. This character of the Greek law of sale is confirmed by the epigraphical material. The formal analysis, and also the content's one, of the Sicilian contracts of Camarina and Morgantina (spanning from iv b. C. to i b. C) compared with that of the contracts of other parts of the Greek world reveal that, despite the absence of juridical complexity, the sale transaction is a very formalized and unified one throughout the Greek world, at least since the fourth century b. C., with a tradition which is probably much older. The structure of these contracts is the following: invocation to the gods or Tyche; date; names of seller and purchaser; verb which defines the kind of transaction; object to be acquired, with the elements which

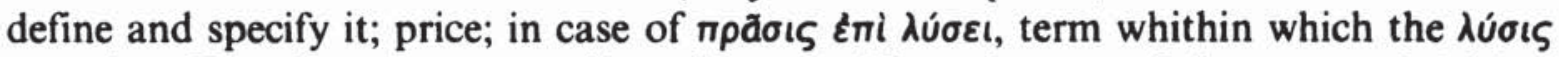

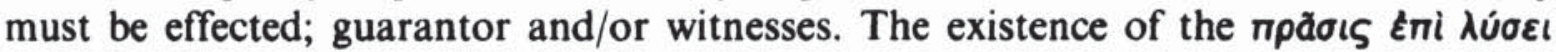
and of witnesses to be added to the written contract even in the latest epigraphical sources confirms the need for formalism and the absence of a complex law, that could cover contracts with the possibility of deferred payment.
\end{abstract}

' Este artículo no ha podido aparecer en el homenaje a J. Untermann (I. J. Adiego, J. Siles y J. Velaza, edd., Studia palaeohispanica et indogermanica J. Untermann $a b$ amicis hispanicis oblata, Barcelona 1994), para el que fue escrito, debido a la premura con que éste se realizó. En las citas se usarán las siguientes abreviaturas: $\mathbf{R}$. Dareste, Recueil (R. Dareste, B. Haussoulier, Th. Reinach, Recueil des Inscriptions Juridiques Grecques, Roma 1965 [ = Paris 1892-1904]); F. Pringsheim, GLS (The Greek Law of Sale, Weimar 1950); M. B. Hatzopoulos, Actes de vente (Actes de vente de la Chalcidique centrale, Atenas 1988); id., Amphipolis (Actes de vente d'Amphipolis, Atenas 1991); L. Dubois, IGDS (Inscriptions Grecques Dialectales de Sicile, Roma 1989); M. I. Finley, Horos-Inscriptions (Studies in Land and Credit in Ancient Athens, 500-200 b. C. The Horos-Inscriptions, Nueva York 1973). 
Las excavaciones de las ciudades sicilianas de Camarina y Morgantina han proporcionado un número considerable de laminillas de plomo con contratos de venta de inmuebles. Su estudio en relación con el de otros contratos del mismo tipo, aunque escasos por ahora, y procedentes de diversas partes del mundo griego, puede aportar más claridad sobre el problema de la ley contractual griega, y, sobre todo, confirmar o matizar ciertas conclusiones a las que F. Pringsheim había llegado en 1950 con su nueva interpretación de la ley de venta griega. Los testimonios epigráficos datan de los siglos IV-II a. C., y, aparte de algunos procedentes de las islas Cícladas, la mayor parte corresponden a dos grandes grupos, por un lado los de Sicilia mencionados, y por otro los de la península Calcídica (Olinto, Torone, Kellion, Smixi) y Anfipolis. Voy a analizar los elementos formales de estas inscripciones para ver si reflejan un sistema unitario, y en qué etapa de la evolución del derecho contractual se encuentran.

En el siglo xIX Savigny y los pandectistas consideraban que la obligación contractual se originaba a partir del libre acuerdo entre las partes interesadas. J. Partsch modifica esta teoría al afirmar que la entrega de arras por parte del comprador imponía la obligatio en los contratos ${ }^{2}$. Sin embargo, el uso de arras no está generalizado en ningún momento del derecho contractual griego, por lo que una nueva interpretación basada en este postulado no es válida. Quien realmente cambia mediante argumentos sólidos la interpretación de la ley de venta griega es $\mathrm{F}$. Pringsheim en 1950, con su obra The Greek Law of Sale ${ }^{3}$. Este autor niega la posibilidad del "contrato consensual» y del carácter de obligatio de acuerdos informales, así como la existencia de una evolución de

2 J. Partsch, Griechisches Bürgschaftsrecht I, Leipzig y Berlín 1909. Para la historia de la interpretación y los principios que rigen el derecho contractual griego, v. H. J. Wolff, «Die Grundlagen des griechischen Vertragsrechts», ZSSR 74, 1957, pp. 26-72.

${ }^{3}$ La reconstrucción de F. Pringsheim de la concepción griega de la compraventa es reconocida en líneas generales, aunque con correcciones y matizaciones, sobre todo en los últimos años, de los distintos aspectos. Cf., por ejemplo, P. Millett ("Sale, credit and exchange in Athenian law and society», en P. Cartledge, P. Millett y S. Todd, edd., Nomos. Essays in Athenian Law, Politics and Society, Cambridge 1990), quien defiende frente a Pringsheim la existencia de venta con posibilidad de pago diferido, existencia que sin embargo no apoyan sus argumentos. R. López Melero («Sobre los orígenes y el carácter de la compraventa en el mundo griego" Gerion 1, 1984, pp. 63-103) matiza las teorías de F. Pringsheim, en concreto sus conclusiones sobre la terminología contractual, basándose sobre todo en el análisis de los términos utilizados en los textos literarios. 
contratos consensuales a contratos formales mediante el uso del documento escrito como elemento de prueba. Por el contrario, afirma que, siguiendo el curso histórico normal, la primera fase de las transacciones legales se caracteriza por su formalismo. Hasta época tardía, la publicidad, elemento característico de las transacciones legales en sociedades orales, era condición necesaria para la creación de obligatio en una transacción ${ }^{4}$. Este formalismo se refleja en los siglos IV y III en los opo hipotecarios áticos, en la costumbre de depositar el documento escrito en manos de un tercero, y en la presencia en todo contrato de testigos. En algunas ciudades griegas parece haber incluso un $\chi \rho \varepsilon \omega \phi u \lambda a ́ k ı v ~ q u e$ asegura el registro y la conservación de contratos privados, y en la ley ptolemaica el derecho contractual tomado de los griegos sigue manteniendo la figura de los testigos que se fija en número de seis, dando al

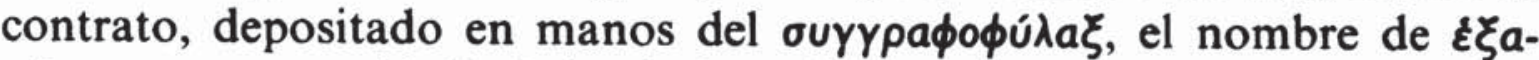

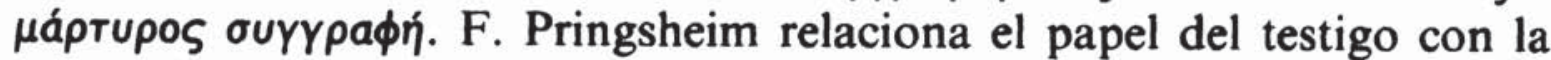
invocación a los dioses en los juramentos de ritos religiosos ${ }^{5}$. Para este autor lo que se produce es la adopción de formas más convenientes que sustituyen un derecho muy formal, pero nunca el reconocimiento de acuerdos informales, y destaca en el caso de Grecia frente a otros sistemas legislativos antiguos, la facilidad de adaptación de las formas legales a la creciente complejidad de las transacciones. Otro aspecto fundamental del derecho contractual es la distinción entre propiedad y posesión, a pesar de que su importancia no aparece reflejada en la terminología jurídica. En la Atenas del siglo Iv todavía no hay ningún término general para definir las ramas de la ley referentes a los problemas de propiedad y posesión, y no existe ninguna oposición terminológica similar a la romana possessio-dominium ${ }^{6}$. Sin embargo, la importancia jurídica de la distinción sí estaba reconocida, como demuestran los contratos de venta, en los que esta distinción es un elemento básico ${ }^{7}$.

${ }^{4}$ Cf. Hesiodo, Op. 371, y Leg. Gort. I 14, 20 ss., III 45-7, etc.

${ }^{5}$ Cf. por ej. la inscripción de Halicarnaso $\left(S I G^{3} 46\right)$ de mediados del s. v a. C. referente a la venta de bienes confiscados por el templo, en que los dioses, y, junto a ellos, los vewnoıal son señalados como garantes.

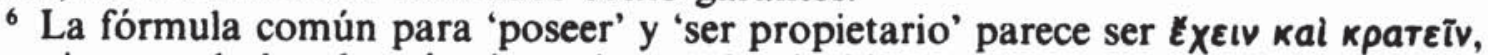
pero ninguno de los dos términos tiene valor jurídico. Lo mismo ocurre con el tér-

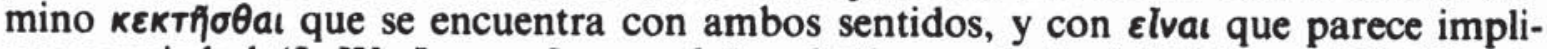
car propiedad (J. W. Jones, Law and Legal Theory, Oxford 1956, pp. 201-202; A. Kränzlein, Eigentum und Besitz, Berlin 1963, pp. 11-21; A. R. W. Harrison, Law of Athens, I, 1968, p. 201).

' Cf. Dem. (VII 26) y Thphr. (Stob., Florileg. 44, 22). Cf. A. R. W. Harrison, op. cit. en nota 6, p. 205: «it is, however, one thing to recognize a difference between possession and ownership and quite another to elaborate the distinction into a who- 
Esta distinción entre propiedad y posesión, y el formalismo caracterizan la ley de venta griega tal y como la define F. Pringsheim en su obra citada, y como parecen aceptar todos los estudiosos del tema desde entonces. Se trata de una ley basada en el principio de «venta al contado", principio vigente en Egipto, Babilonia, Asiria, entre los germanos e incluso en la ley arcaica romana. Entre los griegos el pago del objeto en venta marca el cambio de propiedad, y el contrato escrito es una de las formas para dar publicidad a la transacción y al nuevo propietario, pero no implica obligatio ninguna al haberse realizado la transferencia de propiedad. Un acuerdo previo a la venta es posible, pero no crea más que un debitum y no una obligatio. Los términos $\pi \omega \lambda \varepsilon \omega^{2}$ y ம்véoนa aparecen en Heródoto, en el código de Gortina, Platón, Jenofonte, Aristóteles, Teofrasto y Tucídides con el sentido de negociar una venta o una compra; el término $\delta \phi \varepsilon i ́ \lambda \omega$, que significa el deber del comprador a pagar el precio, no implica responsabilidad jurídica puesto que, mientras éste no pague, no es propietario y el vendedor no tiene nada que reclamar ${ }^{8}$. Para cualquier operación de venta mediante crédito que quisiera realizarse tenía que recurrirse, pues, a contratos ficticios de préstamo que legalizaban la situación e implicaban una obligatio por parte del deudor ${ }^{9}$.

La existencia del contrato, por tanto, sólo servía jurídicamente para establecer el derecho de propiedad, y la importancia del elemento formal de los testigos radicaría en la corroboración de éstos respecto al nuevo propietario, por lo que el contrato tenía que suponer un pago y traspaso de la propiedad simultáneamente. La función jurídica del garante no ha sido claramente definida por ningún estudioso del tema, y en caso de incumplimiento no sabemos si jurídicamente era posible un recurso contra él, o si tan sólo suponía una garantía personal y privada

le body of separate rules for protecting the two different relations to a thing. This the Romans did and the Athenians failed to do".

${ }^{8}$ F. Pringsheim, GLS, pp. 161-7 y 159.

9 Estos préstamos ficticios son necesarios sobre todo en los casos de compra de bienes no definidos, como productos de una cosecha aún no recogida, pero también cuando el comprador, pasando a ser posesor de los bienes, no los puede pagar todavía, por lo que el vendedor le presta el dinero para que se efectúe la compra. Otra variante es que el comprador entregue al vendedor un dppaßúv (fianza o señal) que en origen era un objeto y luego una suma de dinero a título de garantía. El único recurso posible en este caso se da contra el vendedor que, no aceptando el precio de venta, no devuelve las arras. El texto principal a este respecto, de interpretación discutida, es Thphr. en Stob., Florileg. 44, 22, 4-6 (cf. W. Kunkel, ZSSR 69, 1952, pp. 392-5; M. Talamanca, L'arra della compravendita in diritto greco e romano, Milán 1953, pp. 7-10). 
para el cumplimiento por ambas partes contratantes ${ }^{10}$. Parece, pues, que la importancia del contrato residía en su valor de certificado sobre el derecho de propiedad respecto a una cosa, por lo que no pueden existir procesos motivados por incumplimiento del mismo. Tan sólo es posible

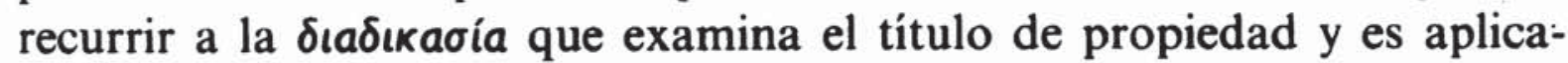
ble, por tanto, a favor del comprador que habiendo pagado no haya adquirido la posesión, o del vendedor que habiendo transferido los bienes no haya recibido su pago, es decir, utilizable siempre por un propietario privado de su posesión ". Cuando la venta se realiza mediante algún tipo de crédito, como éste tiene que ser disfrazado bajo transacción de préstamo, el tipo de procesos aplicables es el de los casos de deuda.

De la misma forma que un préstamo ficticio posibilita una venta con pago a posteriori, una venta ficticia puede servir de garantía para

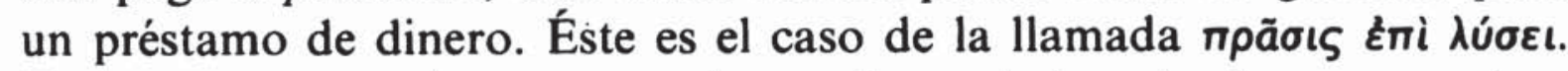
En época muy arcaica un acreedor podía ser indemnizado por una deuda no pagada mediante la persona del deudor o de su hijo - lo que en Atenas fue prohibido por Solón-, o mediante toda su propiedad. Este tipo de indemnización no desaparece del todo en la historia griega, pero en época clásica se modifica con la costumbre de entregar el deudor una parte de su propiedad como garantía, lo que está bien atestiguado a partir del siglo IV-III a. C. Una de las formas de garantía más frecuentes es la hipoteca. Pasado el plazo de pago de una deuda, el acreedor se convertía en propietario de la propiedad hipotecada por el deudor, y podía exigir la posesión mediante reconocimiento judicial de este derecho. Pero en caso de pagarse la deuda en el plazo previsto, la hipoteca quedaba anulada automáticamente ${ }^{12}$. Igual a la hipoteca por su finali-

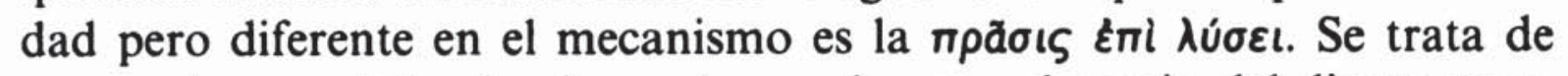
una venta que el deudor hace al acreedor por el precio del dinero prestado, a condición de poder volver a comprar el objeto en cuestión - los testimonios conservados no nos proporcionan ninguna información so-

${ }^{10}$ Seguramente el garante lo era de la responsabilidad que el vendedor, como sabemos que ocurre en otras culturas, tenía ante el comprador. Cf. la ley mesopotámi$\mathrm{ca}$, en la que la protección al comprador estaba establecida y garantizada en el Código de Hammurabi, manteniéndose la tradición en la época neobabilónica y persa. Según esta ley, un arquitecto era responsable ante su cliente si una casa construida por él se venía abajo, y un armador debía pagar las reparaciones y el deterioro de las mercancías si había vendido un barco en malas condiciones (G. Contenau, Vida cotidiana en Babilonia y Asiria, Barcelona 1958, pp. 89-90). Cf. Pl., Leg. 916 a-d.

$"$ Sobre el tipo de procesos que garantizan una protección estatal de la propiedad v. A. R. W. Harrison, op. cit. en nota 6, pp. 206-14.

12 J. W. Jones, op. cit. en nota 6, pp. 238-241; M. I. Finley, Horoi-Inscriptions, pp. 29-31. 
bre posibles intereses - dentro del plazo establecido. M. I. Finley lo define como "sale on condition of release" ${ }^{13}$. Desde el punto de vista del acreedor es la forma de garantía más segura y práctica, pues en caso de no devolución de la deuda ya es propietario de la indemnización, evitándose los problemas de acción judicial. En estas transacciones, como en las hipotecas, es especialmente importante la distinción entre propiedad y posesión, ya que lo más probable en estos casos es que el deudor siguiera disfrutando de la posesión de la propiedad hipotecada o vendida, y que las condiciones establecidas afectaran, al menos en la práctica, sólo al derecho de propiedad y no al de posesión. La interpretación

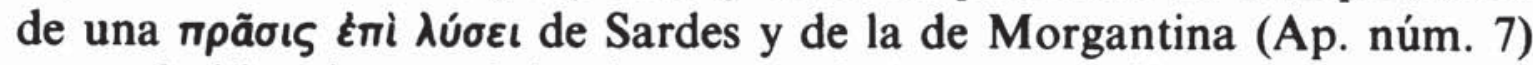
apoya la idea de que el deudor mantenía la posesión ${ }^{14}$.

Los $8 \rho \circ$ - marcas colocadas en una propiedad para información pública sobre el actual posesor y propietario, atestiguados en Ática y ciertas ciudades de Asia Menor entre el 363 y el 259 a. C. - forman el principal testimonio de esta práctica. Aparte de los más de cien 8 pol, los documentos epigráficos que revelan este recurso son más bien escasos (v. Apéndice O-S) ${ }^{15}$.

Los contratos de venta sicilianos presentan un formulario que se repite con mínimas variantes, y que en general, al menos en lo que respecta a los elementos fundamentales, coincide con el del resto de los con-

${ }^{13}$ M. I. Finley, Horoi-Inscriptions, p. 35.

${ }^{14}$ Cf. W. H. Buckler y D. M. Robinson, $A J A 16,1912$, p. 60 ss. para la inscripción de Sardes. Para las diferencias en uso y características entre la hipoteca y la

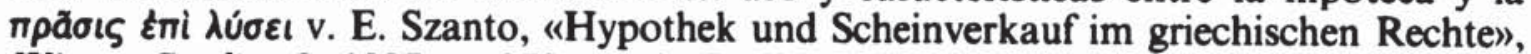
Wiener Studien 9, 1887, p. 279 ss.; A. R. W. Harrison, Law of Athens, I, p. 262 ss., y M. I. Finley, Horoi-Inscriptions, pp. 29-37.

${ }^{15} \mathrm{Cf}$. además el pergamino de Dura Europos (F. Cumont, Fouilles de DouraEuropos, 1922-23, París 1926, pp. 286-96) y una lista de papiros en que la transac-

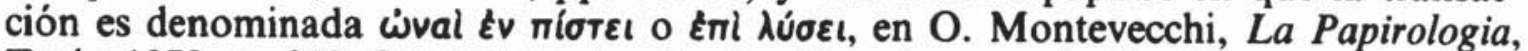
Turín 1973, p. 210. Respecto a las fuentes literarias, en ningún discurso aparece el término; sin embargo, podria reconocerse esta práctica en Demóstenes XXVII 9 ss., XLIX 11 ss. e Iseo V 21, VI 33, X 24. Según M. I. Finley (op. cit. en nota 14, p. 32 ss.) esta misma transacción se realiza también en el discurso de Demóstenes con-

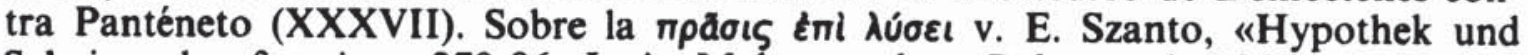
Scheinverkauf...", pp. 279-96; I. A. Meletopoulos, Polemon 4, 1949, pp. 41-72, J. V. A. Fine, Horoi, Hesperia, Suppl. IX, 1951, pp. 143-66; M. I. Finley, op. cit., pp. 31-7; C. Vatin, $B C H 86,1962$, pp. 524-34; E. Berneker, $R E$ Suppl. X, 1965, cols. 652-64. 
tratos privados de venta atestiguados epigráficamente en griego ${ }^{16}$. La

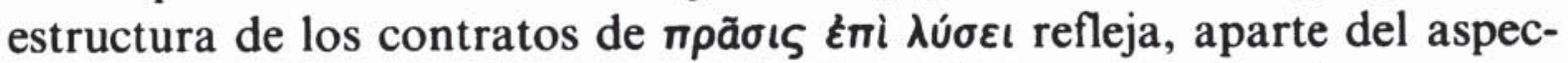
to aparente de venta, las características del contrato de préstamo que esconde la transacción: cambia el verbo que define el contrato, y aparece algún elemento más como la indicación de un plazo para efectuar la

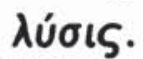

Voy a presentar a continuación el esquema general de los contratos sicilianos, analizando cada una de sus partes y relacionándolas con las de los contratos procedentes de otras zonas de Grecia ${ }^{17}$.

\section{Estructura general:}

1. Invocación a los dioses $y / 0$ a la fortuna.

2. Datación.

3. Nombre del comprador y vendedor.

4. Verbo que define la transacción.

5. Objeto de compra con elementos que lo describen y especifican.

6. Precio.

7. Plazo señalado para efectuar el contrato en los casos de $\pi \rho a ̃ \sigma \iota \varsigma$

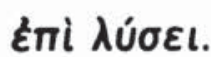

8. Garantes y/o testigos.

1. Curiosamente destaca en los contratos sicilianos la ausencia del primer elemento formal que encontramos en la mayor parte de este tipo de textos, la invocación a los dioses y a la fortuna como introducción. Aparece normalmente con combinaciones de las expresiones $\theta \varepsilon \delta ́ \varsigma$ y

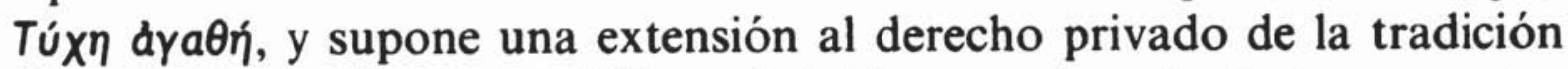
de comenzar todo acto público oficial invocando a la fortuna y a los dioses como testigos, lo que concede una mayor garantía a la transacción ${ }^{18}$. Aunque se repiten casi siempre los mismos elementos, no parece

${ }^{16} \mathrm{Cf}$. la similitud con la estructura de los contratos babilonios, que se rigen por la misma ley de venta (v. A. Leo Oppenheim, Ancient Mesopotamia, Londres 1964, pp. 280-2).

17 Los contratos de venta conocidos en Sicilia son los mencionados en el apéndice bajo los números 1 a 10 (se han excluido un par de documentos que por lo fragmentario de su estado no pueden aportar ningún dato a este tema). La comparación de estos documentos con los de otras zonas de Grecia se hará ejemplificándose con una selección que aparece en el apéndice y a la que se reenvía mediante las letras A-S.

is Ambas expresiones aparecen en las inscripciones del apéndice E-G, J; la invocación a la fortuna en $\mathrm{D}, \mathrm{H}, \mathrm{N}, \tilde{\mathrm{N}}$; a los dioses en $\mathrm{K}, \mathrm{L}, \mathrm{Q}$. Para la frecuencia y variantes de esta fórmula v. S. Reinach, Traité d'épigraphie grecque, París 1885 , pp. 337-338. Para el papel de los dioses como testigos de juramentos en rituales arcaicos cf. por ej. Leg. Gort. III 5-9. 
haber una forma fija ni siquiera entre las inscripciones de un mismo lugar, como vemos en el caso de Olinto (Ap. E-H).

2. A continuación es frecuente la datación, que se indica de la forma normal en cualquier tipo de documento griego, es decir indicando el año por referencia al magistrado epónimo o, tratándose de transacciones en relación con templos, al administrador respectivo. A veces se añade el día y mes.

$\boldsymbol{\varepsilon} \pi i+$ nombre propio en genitivo, mes y día (Ap. 1, 3, 5, 6?)

$\varepsilon \pi i$ lapanódou + nombre propio en gen., mes y día (Ap. 8, 9)

En este caso sí suelen coincidir las formas y su lugar en la inscripción según zonas. En las inscripciones sicilianas se fecha mediante un epónimo, cuyo tipo de magistratura desconocemos en Camarina, y coincide con la del iepámo內os en Morgantina ${ }^{19}$. En ambas ciudades la fecha encabeza el documento. Véase la indicación del mes y el sacerdote epónimo como una constante en las inscripciones de la Calcídica y Macedonia. En Olinto (E-H, S) aparece en general justo delante de la indicación de los testigos, y no detrás de la fórmula propiciatoria como es

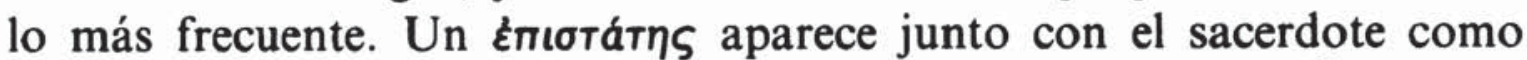
elemento de datación en Ematia (C) y en Anfipolis (M, N, $\tilde{N})$, y sólo en la otra inscripción de Anfipolis (R). En Amorgos (Q) se da el nombre del arconte.

A continuación se especifica la operación comercial indicando:

3. Los nombres de las dos partes contrayentes con el patronímico (Ap. 8, 9, cf. B, D-K), o con el patronímico e indicaciones tribales (en las inscripciones de Camarina núms. 1, 3, 5 y 6, donde se indica mediante numerales la pertenencia a un distrito y a una tribu) ${ }^{20}$. En las inscripciones núms. 3 y 6 faltan las indicaciones de distrito y tribu del vendedor, probablemente por coincidir éstos con los del comprador. En algunos casos aparece tan sólo el nombre propio ( $\tilde{N}, F, R)$.

4. La transacción con indicaciones especificativas sobre ésta.

Ejemplos de verbos usados:

19 Para un paralelo de este cargo en Phintias, v. G. Manganaro, PP 44, 1989, p. 204 y nota 34, con bibliografia.

${ }_{20}$ Para la interpretación de estas abreviaturas como indicaciones de tribu y fratría, basándose en paralelos en Sicilia, v. P. Pelagatti, BA 61, 1976, p. 128 y nota 47, quien atribuye este sistema a la organización ciudadana de época de Timoleonte. Para la organización tribal en Sicilia v. N. F. Jones, Public Organization in Ancient Greece, Filadelfia 1987 , pp. $154-5$ y $173-6$. 
हпріато (Ap. 1, 3, 5, 9, cf. A, B, C, M, N, R)

ம்veĩtai (Ap. 8, 10)

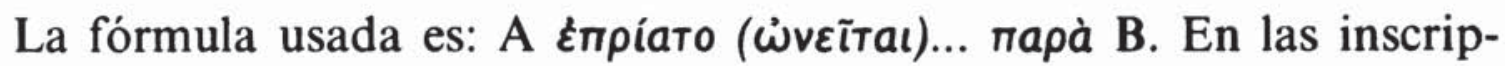
ciones de Olinto, o no aparece ningún verbo indicando el tipo de contrato $(\mathrm{F}, \mathrm{S})$, o, como ocurre en la inscripción de Torone (D), en las de Kellion (I, J, K) y la de Smixi (L), aparece el sustantivo correspondiente a 'compra', $\omega v \eta \dot{~}(\mathrm{G}, \mathrm{H})$ como título del contrato justo después de la invocación a los dioses ${ }^{21}$. El término $\omega \dot{v} \eta \dot{~ v a ~ e s p e c i f i c a d o ~ c o n ~} \varepsilon \dot{u} \theta \varepsilon i a$ en I, con ка́тохоৎ en $\mathrm{J}^{22}$.

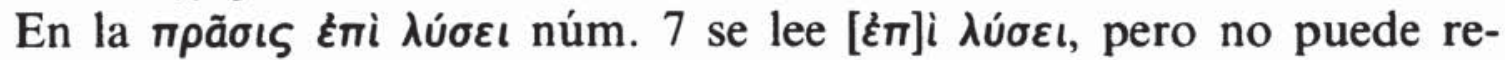
construirse el verbo utilizado. L. Dubois propone la reconstrucción

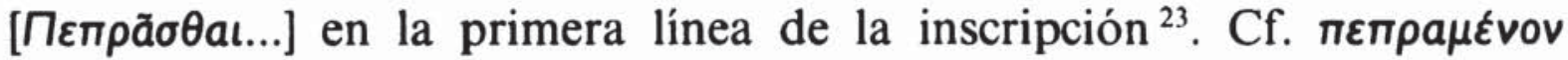

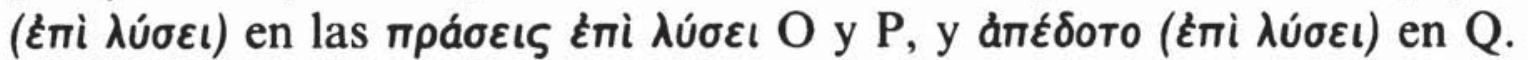

En todas las inscripciones de Camarina en que se puede leer el verbo que define la transacción se usa mpiapal; en las de Morgantina encontramos en un caso прía nios la transacción se define desde el punto de vista de la compra y no de la venta. Lo mismo ocurre en el resto de las inscripciones recogidas

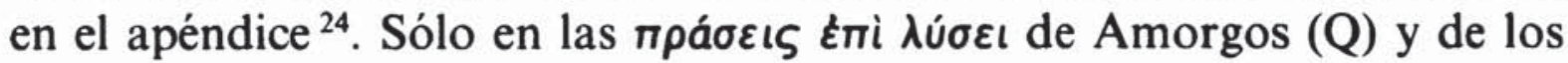
öpo t atenienses $(\mathrm{O}, \mathrm{P})$ el verbo hace referencia a la venta, lo cual evita que se tenga que recurrir a una doble fórmula que refleje el carácter de la compra por parte de una persona y el de la "recompra» por parte de la otra. Hay que tener en cuenta además que en este tipo de transacciones el vendedor es el "protagonista» al ser propietario al comienzo y,

${ }^{21}$ Cf. F. Pringsheim, GLS, pp. 103-11, que señala la frecuencia mucho mayor del tercer tipo (el más antiguo además) de los tres en que él clasifica, según esta cláusu-

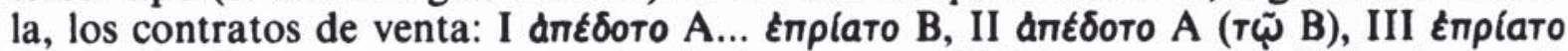

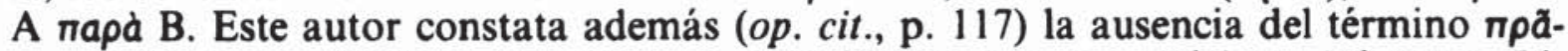
oıs en Homero, Píndaro, los trágicos, Aristófanes, los presocráticos, Isócrates, Lisias, Andócides, Licurgo, Dinarco y Aristóteles, que sólo usan el término npía a correspondiente a 'comprar'.

${ }^{22}$ Un paralelo seguro de la forma $\varepsilon \dot{\theta} \theta \varepsilon i a$ se encuentra en una de las inscripciones de Olinto (D. M. Robinson, TAPA 69, 1938, pp. 52-4); quizá pueda reconstruirse en otras de la misma ciudad (v. D. Hennig, Chiron 17, 1987, p. 148, nota 16). M. B. Hatzopoulos (Actes de vente, p. 64) interpreta estas fórmulas en el sentido de "compra cerrada" y "compra definitiva" respectivamente, como confirmación del carácter de compra-venta en que el objeto de la transacción cambia de propietario realmente, frente a otras transacciones, como una hipoteca o un préstamo, que pueda encubrir un contrato de venta.

${ }^{23}$ IGDS, p. 231.

${ }^{24}$ Este rasgo de la ley de venta se refleja en la irregularidad en el uso, en la diversidad de temas verbales y de sentidos, y en la complejidad en la conjugación de los verbos que significan 'vender' (v. P. Chantraine, "Conjugaison et histoire des verbes signifiant vendre», $R P h, 14,1940, \mathrm{pp} .11-24)$. 
normalmente, también al final de la transacción, y la persona de la que interesa saber que ha perdido la propiedad temporalmente. En la $\pi \rho \tilde{a}-$ $\sigma \iota \varsigma$ ह̇ாi $\lambda u ́ \sigma \varepsilon \iota$ de Anfipolis (R) sin embargo, se utilizan las dos fórmulas

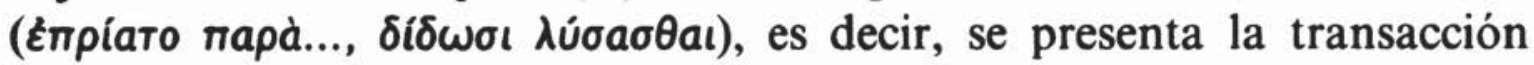
desde el punto de vista del que realiza el préstamo que se esconde bajo la $\pi \rho \tilde{\sigma} \sigma \iota \varsigma$ દ̇ì $\lambda u ́ \sigma \varepsilon \iota$. Esta diferencia se debe seguramente al carácter de

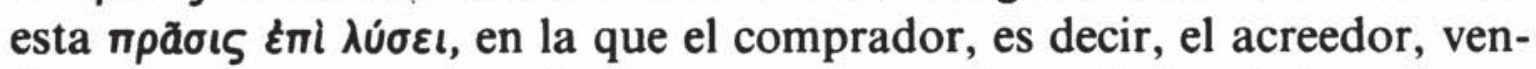
de a un tercero para que le sustituya como tal, manteniendo las mismas condiciones respecto al primer vendedor -es decir, el deudor-. Lo que importa destacar es el cambio de papeles, de ahí la formulación desde el punto de vista del elemento que varía - el nuevo comprador - respecto a la transacción original.

5. Ejemplos de objetos de compra y características que los especifican:

\section{Casas:}

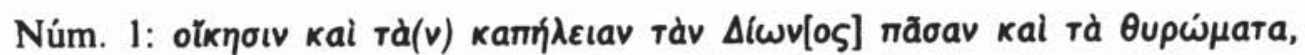

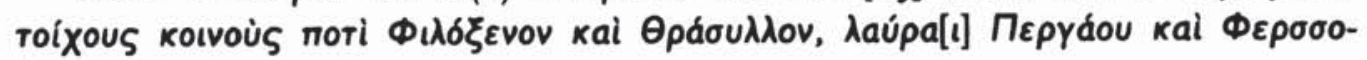
фáoas.

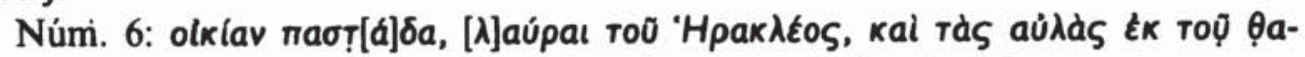

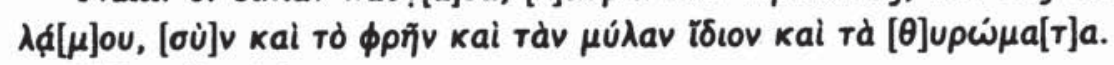

Núm. 9: olkíav.

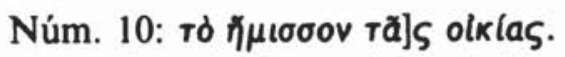

Cf. las inscripciones del apéndice: D-I, S, K.

Tierras:

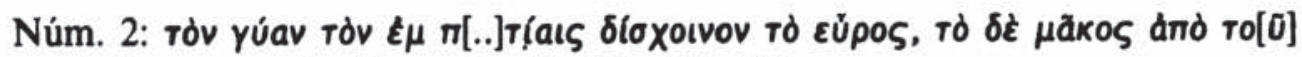

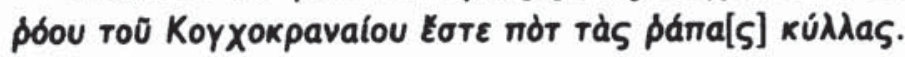

Núm. 5: Toũ X⿳́㇒一

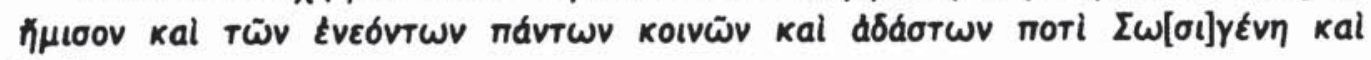
Aplotwva.

Cf. C, L, N, R.

\section{Tierras y casas:}

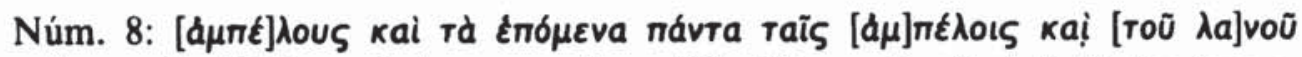

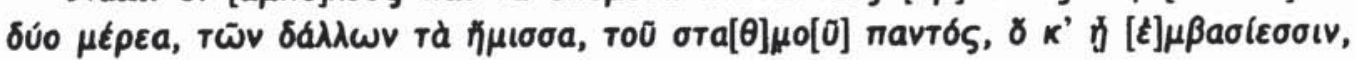

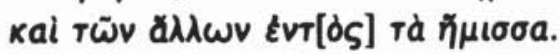

Cf. B, J, M, N, Q.

El elemento que suele aparecer como definidor del objeto de compra es la localización. De las casas en las inscripciones 1 y 6 se indican los 
barrios $^{25}$ en los que se encuentran, el terreno en núm. 2 se especifica mediante los elementos topográficos que lo delimitan, y el de núm. 5 se sitúa en una localidad, y se da el nombre de los propietarios de las tierras colindantes (que coinciden con los vendedores). En general los elementos que especifican el objeto de compra siguen un esquema más fijo en el resto de los contratos que conocemos, sobre todo los de la Calcídica, que en los de Sicilia. La indicación de los vecinos como elemento localizador, que en Camarina encontramos en Ap. 1 y 5, es un elemento fijo en la mayor parte de los contratos de otras zonas (cf. B-I, K, M- $\tilde{\mathbf{N}}$, S). Es de destacar la fórmula peculiar que aparece en los contratos de

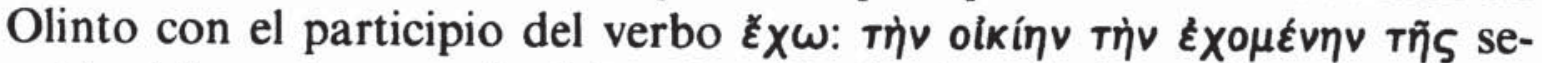
guido del nombre propio del vecino. En las inscripciones de Kellion este mismo dato se refleja con la expresión દ̌́ḱn y el nombre del vecino (I, $\mathrm{K})$. En Anfipolis la fórmula consiste en un pronombre relativo en dativo (en genitivo en $\mathbf{K}$ ) referido al objeto de compra, seguido de la palabra $\gamma \varepsilon i ́ \tau \omega v(\varepsilon \varsigma)$ y el nombre del vecino o vecinos. Los dos sistemas se

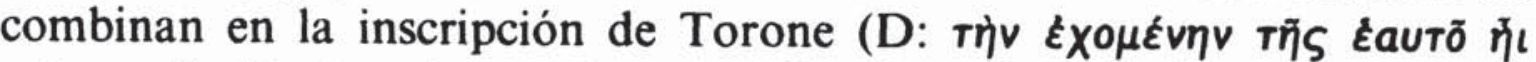

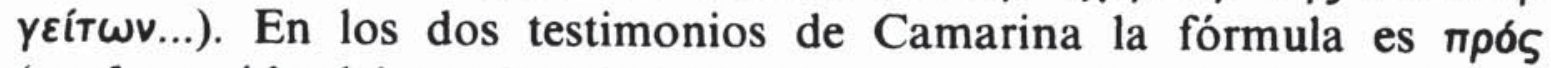
(поті) seguido del nombre de los vecinos en acusativo. Es frecuente informar sobre el propietario anterior del objeto, o la forma en que el vendedor lo había adquirido, elemento importante para evitar disputas o reclamaciones futuras de terceros sobre la propiedad. En Ap. núm. 5

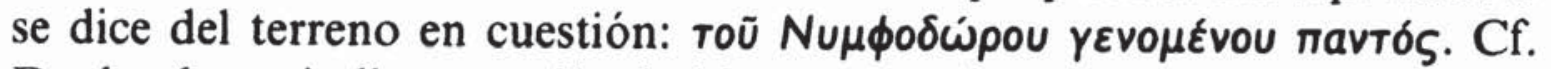
$\mathrm{D}$, donde se indica a quién había comprado el vendedor la casa; $\mathbf{R}$, donde se venden $\varepsilon \operatorname{mi} \lambda \dot{u} \sigma \varepsilon \iota$ tres propiedades, respecto a las cuales se indican el nombre del hermano con el que el vendedor compartía la primera, el nombre del antiguo vendedor de la segunda, y el nombre de la persona que le había hipotecado la tercera; $\mathbf{J}$, donde la vendedora vende todo lo que recibió de una persona que por el nombre podría ser su padre, por lo que probablemente se trate de una herencia; $\mathrm{L}$, donde el vendedor vende un campo del que él mismo era propietario, todo lo que había comprado a una persona, y el terreno que le habia comprado a otra, ambas identificadas en la inscripción. Especialmente interesante

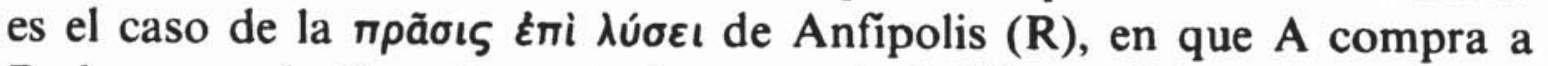

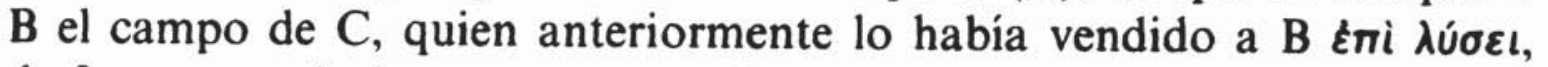
de forma que $\mathrm{A}$ tiene que comprarlo manteniendo el derecho de $\mathrm{C}$ a recuperar mediante pago su tierra, es decir, manteniendo la condición de

${ }^{25}$ Para la interpretación del término גaúpa como 'barrio' en vez de como 'calle', basándose en los daúpapxoı de Tauromenio, v. P. Pelagatti, BA 61, 1976, p. 128 con nota 50 . 
émi $\lambda u ́ \sigma \varepsilon t$. La existencia de una transacción previa - que se deduce de este contrato - es sin duda la razón por la que no se dan en ésta las indicaciones de localización de compra, que no suelen faltar en estos contratos.

Otro tipo de información que proporcionan los documentos es la de objetos adicionales que incluye el contrato. Es de destacar el que siempre se especifique en la compra de casas si se incluyen las puertas y ventanas (núm. 1, 6, cf. B, donde se añade el tejado, y Q). En núm. 6 se indica que la casa es porticada y que incluye los corrales desde el tálamo, la cisterna y el molino; en núm. 1, que incluye una tienda ${ }^{26}$. Cf. $\mathrm{K}$, donde se menciona la inclusión de una azotea, y $\mathrm{N}$, donde se incluye un terreno delante de la casa. En las inscripciones núms. 7 y 8 se especifica que en la venta de la tierra y las viñas van incluidos tà énó $\mu \varepsilon v a$ návтa (en núm. 8 se añaden dos partes de las construcciones vitícolas, la mitad del viñedo y de la instalación que se usa para las operaciones de pisa, y de todo lo que contiene excepto las cosas sagradas) ${ }^{27}$. Cf. B, donde se anota la inclusión en la venta de las aguas de la tierra de labor (cf. núm. 4) y de los bordes ${ }^{28}$, en $\mathrm{R}$ la inclusión de un almacén en la venta de un terreno. En general puede verse una relación entre la riqueza de datos especificando el objeto de compra y el precio del mismo, de forma que cuanto más caro es el objeto más profusión de detalles se encuentra en el contrato.

6. El precio de compra suele ser indicado en último lugar en genitivo.

Diferentes precios en Sicilia según los objetos de compra ${ }^{29}$ :

${ }^{26}$ Probablemente sea 'tienda' el sentido de kanń $\lambda \varepsilon ı a v$. Cf. el sentido de 'comercio al por menor' que tiene el término en Pl., Leg. 849 d, 918 d, y Arist., Pol. 1256 a. Para la importancia económica del texto, que refleja la relación entre lugar de habitación, de producción y venta, y para el sentido concreto de 'tienda de alimentos' $v$. C. Ampolo, «Il nuovo contratto di Camarina», PP 40, 1985, pp. 365-6.

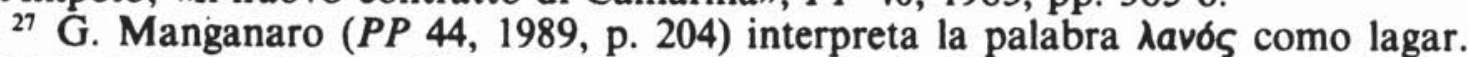
L. Dubois (Bull. Epigr., 1990, p. 859) señala que el término se encuentra en Teócrito (VII 25) con el sentido de edificios de una explotación agrícola, y propone con reservas para la 1. 4: $\delta \boldsymbol{\kappa}^{\prime} \delta[\hat{\varepsilon}] \mu \beta a \sigma i \varepsilon \sigma \sigma \iota v$ en vez de la propuesta de G. Manganaro (op. cit., p. 203): $\delta^{\prime} \eta^{\prime}[\varepsilon] \mu \beta a \sigma(\zeta \varsigma) \varepsilon \sigma(\tau)(v$. Para la interpretación de $\tau \tilde{\omega} v \delta a ́ \lambda \lambda \omega v$ v. G. Manganaro, op. cit., p. 204, nota 38.

${ }^{28}$ Traduzco el término oxarı́s literalmente por «bordes» ya que no está claro a qué se refiere, y traducciones como la de Dareste (Recueil, p. 81), "dependencias», implican realidades no evidentes en el texto.

${ }^{29}$ El valor del talento siciliano es difícil de establecer debido a incongruencias entre las distintas fuentes literarias, y entre éstas y las epigráficas (v. S. C. Langher, "Il Sikelikon Talanton nella Sicilia antica», Helikon, 1963). M. H. Crawford (Coinage and money under the Roman Republic, Londres 1985, p. 344, App. L) ha intentado deshacer estas incongruencias, llegando a establecer el valor como equivalente a 24 
Por la mitad de una tierra, 250 talentos $=6.000$ dracmas (5).

Por una casa y una tienda, 40 talentos $=960$ dracmas (1).

Por unas viñas con sus pertenencias, dos partes de las construcciones viticolas, la mitad del viñedo y del cortijo y todo lo que contiene excepto las cosas sagradas, 21 talentos y 115 litras $=c .516$ dracmas $^{30}(8)$.

Por una tierra, 21 talentos $=504$ dracmas (3).

Por una casa porticada con corrales, un molino y una cisterna, 5 talentos $=120$ dracmas (6).

Por la mitad (?) de una casa, 5 (?) talentos $=120$ dracmas (10).

Por una casa, 4 talentos $=96$ dracmas (9).

Cf. precios en otras zonas ${ }^{31}$ :

Por casas con terreno:

Por la casa, campo, canales, etc., de la inscripción de Tenos (B), 6.000 dracmas ${ }^{32}$; por una casa y tierra en Atenas, 7.000 dracmas (O), y 3.240 dracmas (P); por una tierra, casa, alfar y dos tierras más en Anfipolis, 5.000 dracmas $(\mathrm{Q})$, y por una casa con terreno, 73 estateres de oro $(\mathrm{N})^{33}$; por un terreno (?), unas viñas y unas casas en Kellion (J), 300 dracmas.

\section{Por terrenos:}

Por un campo de cultivo, una tierra y otras cosas en Smixi (L), 1.240 drac-

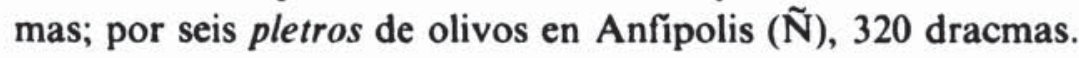

\section{Por casas:}

Por la casa de la inscripción de Torone (D), 112 dracmas; por casas de Olinto (E), 230 dracmas, (S), 2.000 dracmas, (G), 410 dracmas; por una casa en Kellion, 40 dracmas (I), y por otra, 232 (K); por la casa, almacén y «contratados" (o tiendas ${ }^{34}$ ) en Olinto (H), 5.300 dracmas; por casas y fincas de Anfipolis, 12 estateres y medio de oro filipeos (M).

dracmas áticas. Cf. G. Manganaro en R. Romeo, ed., Storia della Sicilia, II, Nápoles 1979, pp. 429-30. La indicación en dracmas señalada a continuación para cada venta está realizada siguiendo la equivalencia de un talento $=24$ dracmas establecida por Crawford.

${ }^{30}$ G. Manganaro, $P P 44,1989$, p. 204 interpreta la cantidad de 115 como dracmas.

${ }^{31}$ La interpretación de los signos epicóricos con los que se indican los precios en Olinto se debe a M. N. Tod ( $A B S A 37,1936-7$, p. 248 s.). Cf. J. W. Graham, Phoenix 23, 1969, pp. $347-58$ para los numerales de Olinto y Anfipolis.

${ }_{32}$ Por otros objetos más simples como una casa sola en inscripciones del mismo registro, los precios oscilan entre 1.700 y 2.000 dracmas (v. IG XII 5, 262).

${ }_{33}$ M. B. Hatzopoulos (Amphipolis, pp. 42-3) señala el distinto uso de dracmas o estateres en los contratos, según daten de antes o después de la incorporación de Anfipolis a Macedonia. Para la acuñación en Anfipolis de estateres de oro durante el siglo Iv a. C., cf. G. Le Rider, Le monnoyage d'argent et d'or de Philippe II frappé en Macedoine de 359 à 294, 1977.

34 Cf. D. M. Robinson, TAPA 65, 1934, p. 128. 
Los precios de venta de una casa parecen oscilar entre 100 y 2.000 dracmas, aumentando hasta 6.000 ó 7.000 cuando a la casa se añaden tierras y otras dependencias o accesorios (hay que tener en cuenta las oscilaciones posibles del dracma dependiendo de zonas). Aparte de los datos epigráficos señalados tenemos algunos literarios como Iseo (IX 42), que habla de una casa comprada en Melite por 3.000 dracmas, en Eleusis por 500, y (V 29) de una en Atenas por 5.000 dracmas. Sin embargo, muchos de los precios que oscilan entre 100 y 500 dracmas para casas en Olinto y Torone no parecen corresponder al valor real de dichas casas, lo que ha llevado a D. Hennig a pensar que en estos casos el contrato de venta esconde una transacción más compleja, probablemente

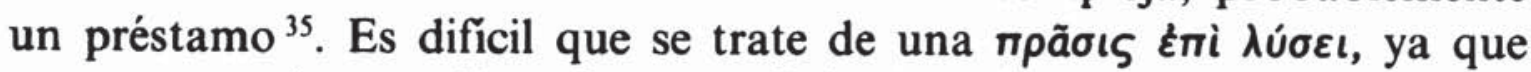
no aparece ninguna fórmula que refleje el carácter de préstamo, como un plazo de tiempo para la devolución de éste, o la expresión éri $\lambda u ́ \sigma \varepsilon ı$. Además, al ser ésta una venta real, el precio sí suele corresponder al valor real. Es posible que se trate de casas hipotecadas, cuyo valor sería, debido a su condición, muy inferior al real (una propiedad hipotecada

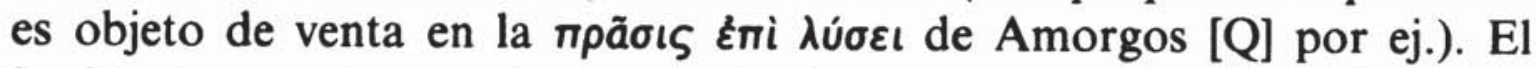
hecho de que algunas de las inscripciones se hayan encontrado en las casas en cuestión apoya esta idea, ya que el valor de opos de este tipo de contrato no tiene mucho sentido si se trata de una compra definitiva y consumada. Las grandes diferencias de precio en los contratos de Sicilia sí podrían responder al valor real, si bien las diferencias entre los precios de las inscripciones 1 y 8 resultan extrañas dados los objetos de compra, y las cantidades de 4 y 5 talentos parecen muy bajas para las casas en las inscripciones 9, 6 y 10 . Si se admite la posibilidad de que, en contra de los indicios arqueológicos, las casas de hallazgo en Olinto no sean las mencionadas en los contratos sino las de los depositarios (v. apartado 8), y se tienen en cuenta todas las posibilidades de diferencias de tamaño, materiales de construcción, calidad, elementos incluidos no mencionados, etc., no se puede descartar que sí se trate en todos los casos del valor real.

Los nombres de comprador y vendedor, el tipo de contrato y el objeto y precio de compra (apartados 3-6) se señalan a la vez en una misma cláusula que suele presentar el mismo esquema, aunque con variantes en la colocación de los distintos elementos:

nombre del comprador-verbo de compra-objeto de compra-nombre del vendedor-precio.

35 D. Hennig, Chiron 17, 1987, pp. 150-5. 


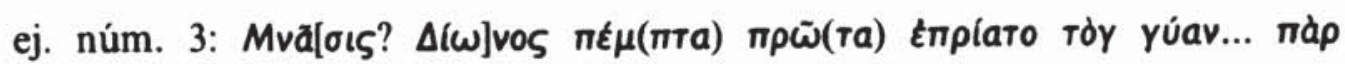
'Ađávios toũ Baoía évòs ǐxarı talávtwv (cf. núm. 1, 4?).

En núms. 5, 6, 8 se invierte el orden de los dos últimos elementos. En núm. 9 se invierte el orden del verbo y el objeto de compra. En núm. 8, además, el nombre del comprador aparece detrás del objeto de compra.

7. Indicación de plazo de tiempo para cumplir el contrato puede

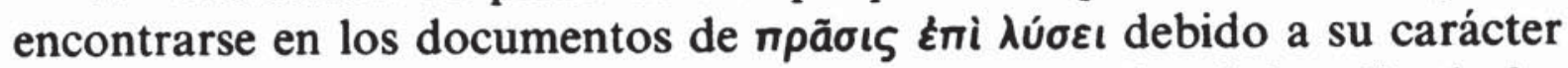
de préstamo encubierto. En el contrato de Morgantina (núm. 7), el plazo es de un año con derecho, por parte del comprador, a ser propietario definitivamente a partir de los seis meses en caso de que el vendedor

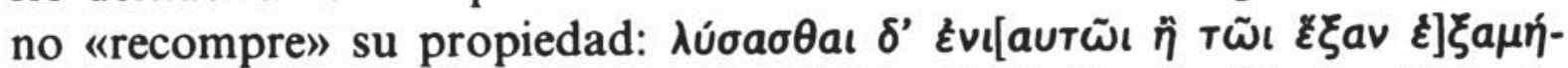

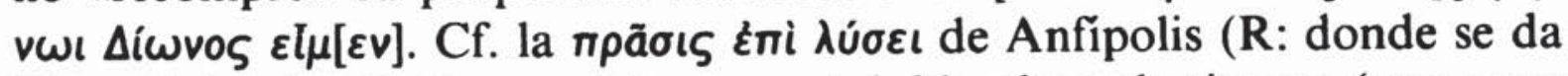
libertad de plazo). Un paralelo para el doble plazo de tiempo (uno para realizarse la "recompra», otro para efectuar el cambio de posesión) se encuentra en la $\pi \rho \tilde{\sigma} \sigma \iota \varsigma$ ह̇mi $\lambda u ́ \sigma \varepsilon ı$ que se realiza en Sardes en el s. III a. C. entre un particular y el templo de Ártemis Sardiane ${ }^{36}$. Esta distinción entre los plazos para el cambio de la posesión y de la propiedad concuerda con la idea de que, en la mayor parte de los casos, el deudor mantiene la posesión aunque la propiedad haya sido transferida a modo de garantía. El término e

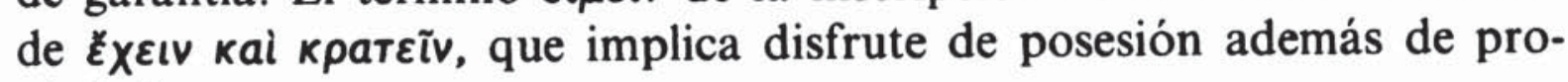
piedad.

8. En la mayor parte de las transacciones económicas aparece en último lugar la indicación de los testigos y/o garantes en nominativo, cuyo nombre genérico varía según las zonas de Grecia, sin que sea posible mediante los testimonios conservados establecer en la mayor parte de los casos sus funciones exactas ni las posibles diferencias de contenido entre los distintos términos. En algunos casos, como en los contratos de Anfipolis, encontramos enumeración de garantes y enumeración de testigos por separado, en otros sólo aparece un término que bien puede referirse a los garantes de la transacción, bien a personas que cumplan las funciones de testigos y garantes a la vez. La ley griega distingue claramente entre las obligaciones del garante y las del vendedor. La función exacta de los garantes no está claramente indicada en ningún testimonio antiguo, pero a través de lo que hemos visto sobre el derecho contractual griego - del concepto griego de la venta al contado - y de los testimonios epigráficos, puede suponerse que los garantes lo eran por lo general del vendedor, y tenían la función de asegurar el cumpli-

${ }^{36}$ W. H. Buckler-D. M. Robinson, $A J A$ 16, 1912, pp. 11-82; id. Sardis VII I: Greek and Latin inscriptions, Leiden 1932, núm. 1. 
miento del contrato mediante el traspaso de la posesión por parte del vendedor, y de proteger al comprador frente a posibles exigencias o re-

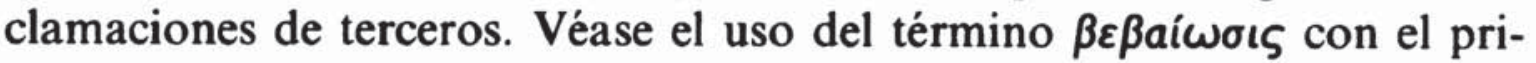
mer sentido en Jen., $A n$. VI 6, 17, CIA II 1058, 21, y sobre todo Din.

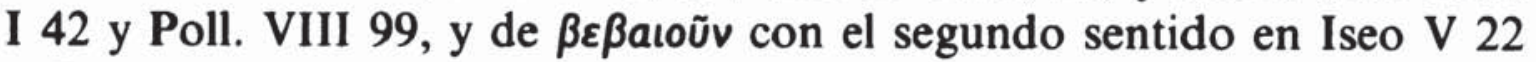
y Dem. XXXVII 12. Asimismo, las fuentes literarias hablan de la $\beta \varepsilon$ -

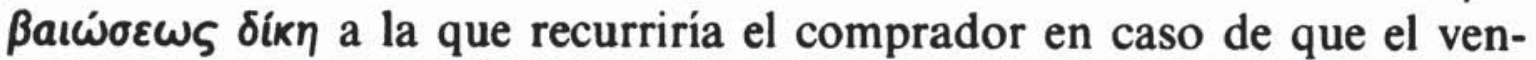
dedor o garante no quisiera protegerle frente a reclamaciones de un tercero (Harp., Poll. VIII 34 ss.). En relación con estos términos es signifi-

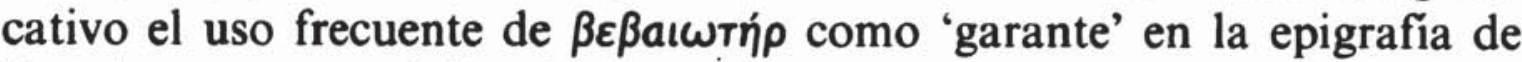

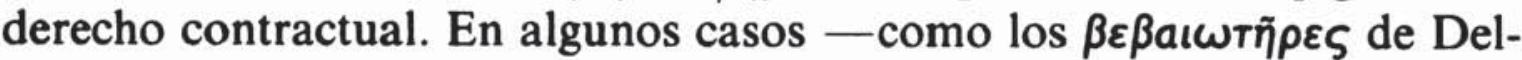
fos (Syll. 449, 4; 457, 15) - existen incluso 'garantes' del comprador que parecen reafirmar esa protección frente a terceros. En el Egipto ptolemaico existe el $\pi \rho \circ \pi \omega \lambda \eta \pi \dot{r} s$, junto al $\beta \varepsilon \beta a \iota \omega T \eta \dot{s}$, aunque pronto el vendedor se convierte en garante de sí mismo (v. por ej. P. Grenf. II 23a, del 107 a. C., y P. Amh. 51, del 88 a. C.).

Los términos atestiguados para designar a los garantes y testigos son:

ăнnохо: término empleado en las inscripciones sicilianas. D. Comparetti interpreta este término sencillamente como 'garantes' ${ }^{37}$. K. Lat-

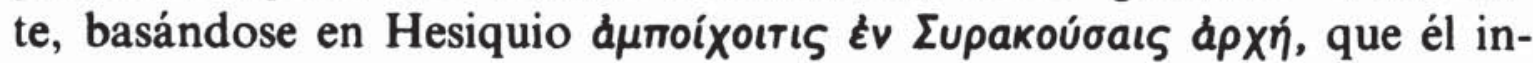

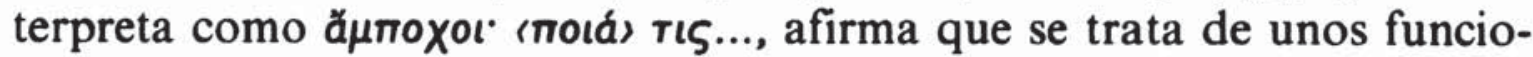
narios encargados de vigilar y conservar los contratos, lo que encajaría con la existencia de una institución no infrecuente en ciertas zonas de Grecia a partir del siglo III o incluso finales del Iv a. C. ${ }^{38}$ Para U. Sicca, que también se basa en la glosa de Hesiquio, los äнmохо son magistrados, y señala como paralelo el papel de los áyopavóroı en el Egipto ptolemaico y romano, citando a Peyron (Papyri Graec. II 8, fr. 6): $\varepsilon \theta \dot{\eta} \mu \varepsilon \theta a$

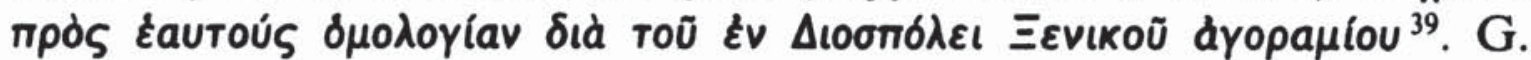
Manganaro los interpreta como ciudadanos particulares que asumen el papel de garantes o testigos de un negocio, lo que dados los paralelos epigráficos señalados, y su calidad de vecinos o parientes de los contratantes en algún caso, parece lo más probable ${ }^{40}$.

Cf. los términos empleados en las inscripciones de otras zonas ${ }^{41}$ :

${ }^{37}$ D. Comparetti, «Laminetta argentea iscritta di Aidone (Sicilia)», Annuario della Regia scuola archeologica de Atene 1, 1914, p. 115.

${ }^{38}$ K. Latte, Gnomon 3, 1927, pp. 371-2. 165-6.

${ }^{39}$ U. Sicca, Grammatica delle Iscrizioni doriche della Sicilia, Arpino 1924, pp.

40 G. Manganaro, $A S N P 7,1977$, p. 1344.

${ }^{41}$ Otros términos son: пробтátal en las inscripciones de Tespiae, de los que G. Colin ( $B C H 21,1897$, p. 564) dice «il s'agit toujours des gens qui se portent caution 


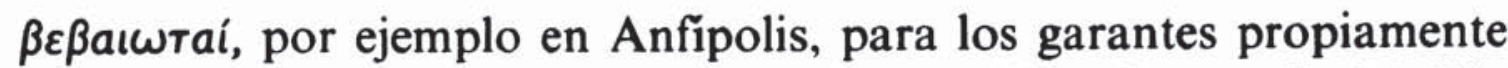
dichos (M, N), en Olinto (E, F, G, H, S), en Kellion (I) y en Smixi (L). пратп̃рєऽ en las inscripciones de Tenos, aunque en el número 41 en-

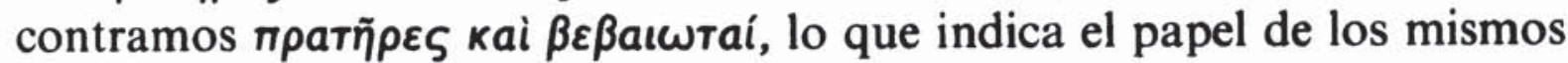
vendedores como garantes ${ }^{42}$.

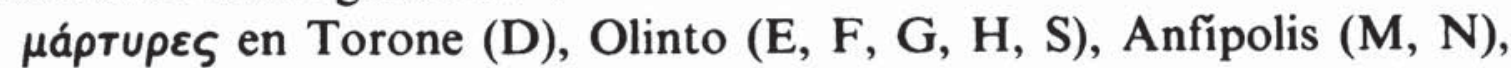
Kellion y Smixi (I-L). En la inscripción de Pech Maho (A), Anfipolis $(\tilde{N})$, y en las de Kellion ( $\mathrm{J}$ y $\mathbf{K}$ ), donde aparecen solos, probablemente desempeñen la función de garantes a la vez que la de testigos, aunque cabe la posibilidad de que por determinadas razones los garantes sean omitidos (v. infra).

Ejemplos de números de garantes, distinción o no entre garante y testigo, y posible relación con el precio de venta:

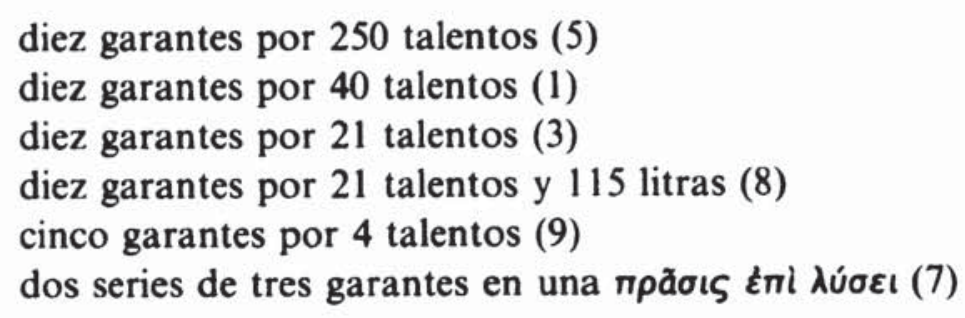

Cf. siete garantes por 6.000 dracmas (B)

dos garantes y, por lo menos, cuatro testigos (C)

un garante y tres testigos por 112 dracmas (D)

dos garantes y tres testigos por 230 dracmas (E)

dos garantes y tres testigos por 2.000 dracmas (S)

un garante y tres? testigos $(F)$

un garante y tres testigos por 410 dracmas $(G)$

un garante y tres testigos por 5.300 dracmas $(\mathrm{H})$

un garante y tres testigos por 40 dracmas (I)

tres testigos por 300 dracmas $(J)$

tres testigos por 223 dracmas $(\mathrm{K})$

un garante y dos testigos por 1.240 dracmas (L)

un garante y tres testigos por 12 estateres y medio de oro filipeos (M)

cuatro garantes y tres testigos por 73 estateres de oro $(\mathrm{N})$

tres testigos por 320 dracmas $(\tilde{N})$

cuatro testigos $(\mathbf{R})$

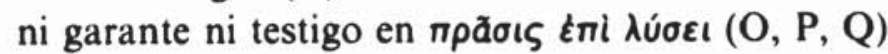

Por los testimonios presentados no parece haber ninguna relación entre el número de garantes y el precio de venta, por lo que a falta de

du paiement»; Eyyuo en Hipata (IG IX [2] 4), Efeso (SIG 364, 41), Samos (SIG 976, 13); દ̇ákō en las laminillas de Corcira (P. Calligas, "An inscribed lead plaque from Korkyra", $A B S A 66,1971$, p. 85).

42 Sobre los garantes en el registro de Tenos v. R. Dareste, Recueil, pp. 97-101. 
más información no puede sino pensarse que el número es arbitrario y dependiente de la elección de las partes contratantes en la transacción, o que sigue la costumbre local en cada caso ${ }^{43}$. En Sicilia el número de 10 es casi una constante. En Torone (D), Anfipolis (M, N) y Olinto (E$\mathrm{H}, \mathrm{S}$ ) parece costumbre el uso de garantes y testigos, siendo de destacar la proporción de uno y tres respectivamente. En las inscripciones de Anfipolis ( $\tilde{N}, \mathbf{R})$ y las de Kellion (J y K) resulta extraña la aparición exclusiva de los testigos y, aunque no hay suficientes elementos de juicio, es lógico suponer que éstos ejercieran a la vez la función de garantes ${ }^{44}$. Los únicos casos en que no hay indicación ni de garantes ni de

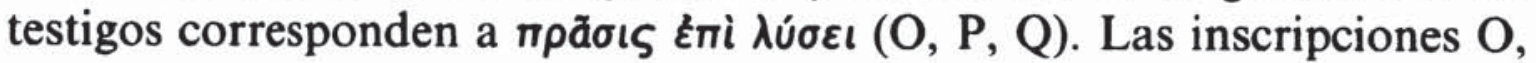
$P$ son 8 po ‘ áticos cuya función es hacer público el contrato, pero que probablemente sólo repetirían los datos necesarios para revelar el tipo de transacción, de un contrato depositado en otro lugar, donde sí aparecerian los garantes ${ }^{45}$. La ausencia de garantes y testigos en la inscripción de Amorgos $(\mathrm{Q})$ resulta extraña, pero podría pensarse que las personas relacionadas con los objetos en venta, que se mencionan en la inscripción, ejercieran esa función tan propia de ellas como se verá más

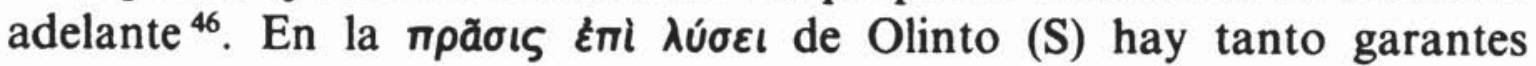
como testigos, y en la de Morgantina (7) dos series de testigos. Según

${ }^{43} \mathrm{Cf}$. Pl., Leg. 953 e, donde establece que quien se responsabilice de una garantía debe señalarlo en un documento escrito ante no menos de tres testigos si se trata de una cantidad menor de 1.000 dracmas, y no menos de cinco si la cantidad es superior.

${ }^{44} \mathrm{La}$ explicación de M. B. Hatzopoulos (Actes de vente, p. 26) para la ausencia de garante en $K$, basada en que éste suele ser el antiguo propietario, que en este caso era el difunto padre de la heredera, no me parece convincente debido a que la identidad del garante con el propietario anterior no parece ser en absoluto una norma fija en estas transacciones, y porque, aunque así fuera, no creo que al comprador le satisfaciera la justificación de defunción para la falta de un elemento tan importante, cuando podía buscarse un sustituto, incluso pariente cercano del difunto, con tal fin. El mismo autor interpreta la ausencia de garantes en $\tilde{\mathbf{N}}$ como debida sin duda al hecho de que el macedonio Asandro (el vendedor) había adquirido los viñedos por una distribución de tierras tras la conquista macedonia, y no mediante compra (Amphipolis, p. 58). Ambas interpretaciones se basan en hipótesis que no pueden confirmarse. En el caso de la inscripción $\mathbf{R}$, sin embargo, el hecho de que se trate de una transformación respecto a una transacción anterior, hace muy probable que la omisión de los garantes se deba a que aparecen en el primer contrato, como seguramente también la falta de detalles - por ejemplo, la localización- especificando los objetos de compra.

${ }^{45}$ Cf. M. I. Finley, Horoi-Inscriptions, núms. 13, 17, 27, 32, etc.

46 Aunque por lo detallado del contrato esta inscripción se diferencia de los $8 \rho \circ$, tiene en la ausencia de garantes y testigos un elemento común con éstos. M. I. Finley la incluye entre los 8 pol (Horoi-Inscriptions, núm. 102), aunque destacando las diferencias. 
D. Comparetti esta doble serie corresponde a las dos fases de la trans-

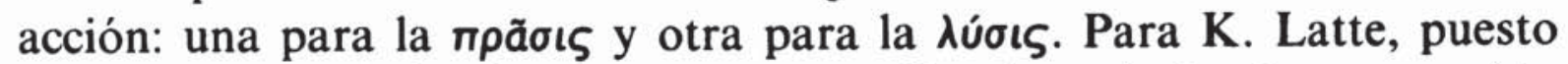
que interpreta el término ä $\mu$ похо como 'funcionarios' y la transacción se realizaría en el transcurso de más de un año, las dos series corresponderían a los funcionarios de cada año. La hipótesis que parece más aceptable es la de Arangio-Ruiz, Olivieri y De Sanctis, quienes mantienen que cada parte tenía sus garantes ${ }^{47}$. El garante común sería el custodio del documento según los primeros, mientras que según el tercero serían más de uno los testigos comunes a ambas partes. G. De Sanctis proporciona un paralelo que apoya esta interpretación en el documento de reconocimiento de deuda a los elisfasios (población arcadia) por parte de los epidaurios. El texto está dividido en dos partes que expresan el préstamo y el cobro de la deuda respectivamente, e indican garantes para cada una de las partes implicadas. La propuesta de D. Comparetti recuerda los testimonios de $\pi \rho \tilde{a} \sigma \iota \varsigma$ émi $\lambda u ́ \sigma \varepsilon \iota$ del Egipto ptolemaico

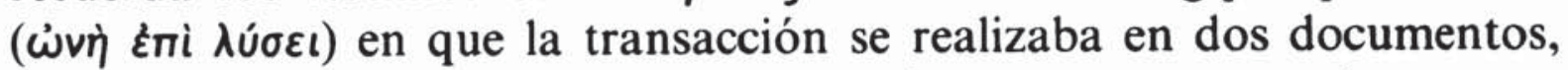
uno de compra y otro de préstamo, cada uno con sus testigos, pero existe una diferencia significativa, y es que en Egipto ambos documentos son completamente independientes. La interpretación de K. Latte, dado el sentido que hemos aceptado aquí para el término ă $\mu$ похоı, queda descartada ${ }^{48}$. La coincidencia entre algunos de los nombres de los garantes hace pensar que pudieran estar relacionados, y no son pocos los casos en que los garantes son elegidos por el vendedor de entre sus parientes $^{49}$. Pero quizá la interpretacićn más plausible sea la de $S E G$ IV 62 , mantenida por L. Dubois (IGDS, pp. 231-3), para quienes se trata de una repetición, por razones desconocidas, de los mismos nombres (v. la lectura nueva que se hace en estas dos obras de algunas de las secuencias de letras de las listas de garantes). También podría pensarse que el pago se había realizado en dos plazos, correspondiendo cada lista de testigos a uno de ellos (cf. la inscripción A de Pech Maho).

Hay casos en que una persona es garante por una cantidad fija, como se ve en la inscripción de Tenos (B) en que dos garantes lo son кarà xılías (v. además los números 23 y 32 del mismo registro en $I G$

47 V. Arangio-Ruiz y A. Olivieri, Inscriptiones Graecae Siciliae et infimae Italiae ad ius pertinentes, Nápoles 1925, pp. 141-2; G. De Sanctis, «Un pagamento degli Epidauri», $R F C$ 56, 1928, pp. 523-7.

${ }_{48}$ Cf. además G. De Sanctis, loc. cit. (nota 47) en contra de esta propuesta.

49 G. Manganaro (ASNP 7, 1977, p. 1344) y de G. De Sanctis (op. cit., p. 526). En este caso no podemos establecer ninguna relación entre garantes y vendedor $o$ comprador (es decir, deudor o acreedor) ya que tan sólo se conserva el nombre de pila del segundo. 
XII 5,872 ), y en relación con esto es destacable la fórmula $\mu \varepsilon \delta \sigma \omega ı$ náv-

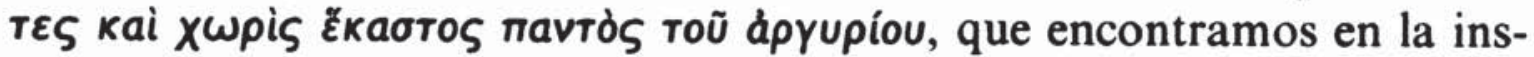
cripción B (= núm. 36) y en otras del mismo registro, en que se especifica claramente la obligación de cada garante respecto al total ${ }^{50}$. La existencia de una garantía por una cantidad del precio total hace pensar que los garantes eran responsables del estado material del objeto de compra, o bien que se hacian responsables de devolver al comprador la cantidad señalada si se demostraba invalidez del contrato por no ser el vendedor propietario del objeto vendido.

Es frecuente que los garantes pertenezcan a la familia del vendedor. $\mathbf{R}$. Dareste señala que en algunos casos eran elegidas además personas que tuvieran un derecho sobre la propiedad vendida, pues eso suponía una mayor seguridad para el comprador, ya que el garante confirmaba que el vendedor era realmente propietario, lo que tenía gran importancia en el caso de Grecia, donde las disputas por cuestión de la propiedad eran frecuentes ${ }^{51}$.

Ejemplos de garantes emparentados con el vendedor:

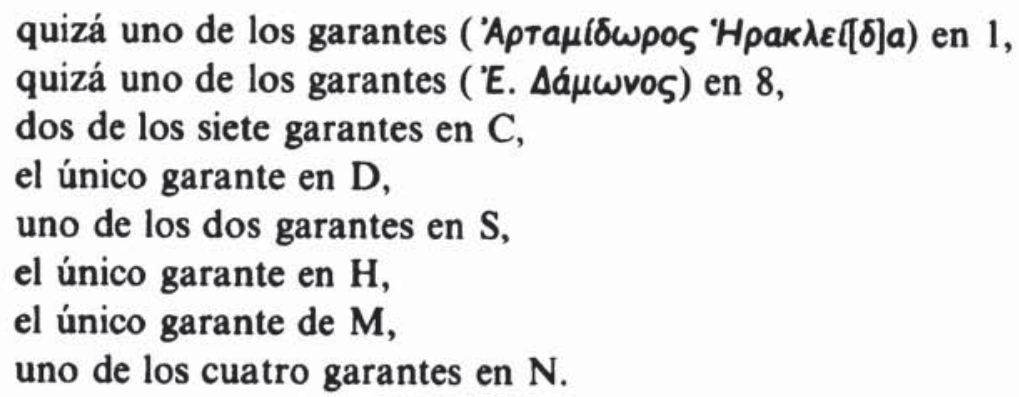

La existencia de garantes parientes del comprador en las inscripciones núms. 12 y 18 del registro de Tenos (IG XII 5, 872) se explica porque a su vez habían sido garantes de una transacción previa en que el actual comprador había sido el vendedor ${ }^{52}$. No es probable que el garante sea responsable en estos casos de que el comprador pague el precio, ya que ello implicaría la posibilidad de la venta a crédito.

Es de destacar que en los casos en que hay testigos además de garantes es frecuente que entre ellos figuren vecinos de la casa comprada, lo que es fácil de explicar dadas las ventajas que la proximidad conlleva para esta función.

so Cf. E. Szanto, «Hypothek und Scheinverkauf im griechischen Rechte», Wiener Studien 9, 1887, pp. 289-91.

s1 R. Dareste, Recueil, p. 97 ss., y E. Szanto, Wiener Studien 9, 1887, p. 291 s.

s2 R. Dareste, Recueil, p. 97 ss. 


\section{Ejemplos:}
uno de los testigos en $\mathrm{E}$, dos de los tres testigos en $\mathrm{S}$, uno de los tres testigos en $\mathbf{G}$, uno de los tres testigos en $\mathbf{H}$, uno de los testigos en $\mathrm{K}$.

Uno de los testigos en I podría ser hermano del vecino, y el garante el vecino mencionado ${ }^{53}$.

En la inscripción $\mathrm{L}$ uno de los testigos probablemente sea un hijo de la persona a quien el vendedor había comprado parte del objeto de venta de este contrato.

9. Un elemento que hasta ahora sólo está atestiguado en dos de los contratos de Camarina (Ap. núms. 1 y 5 , y quizá en 2) es el del

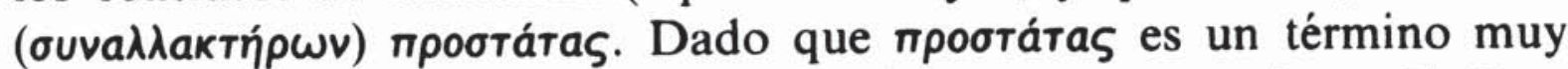
genérico de numerosas aplicaciones, podría aceptarse aquí con F. Cordano que se trata del árbitro entre los contrayentes y no de un presidente oficial del tipo de los atestiguados para el consejo de Gela, Agrigento, Acras, Siracusa e incluso Tauromenio, como propone F. Sarto$\mathrm{ri}^{54}$. Según C. Ampolo el papel del пробтáтаs podría ser paralelo al de los áfuvvófoı en los contratos de venta de terrenos y casas del catálogo de Tenos; esta figura podría relacionarse con la costumbre de registrar

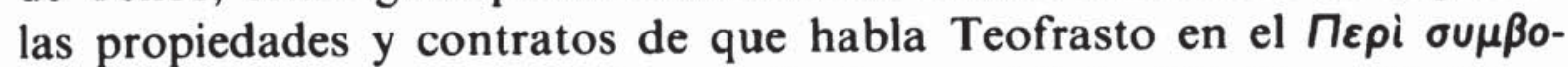

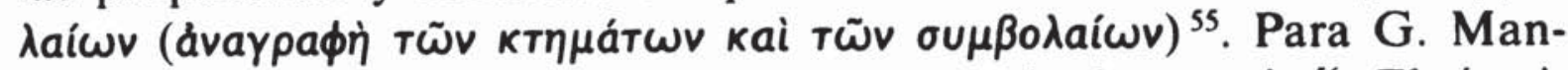
ganaro, el término hace referencia a una especie de notario ${ }^{56}$. El térmi-

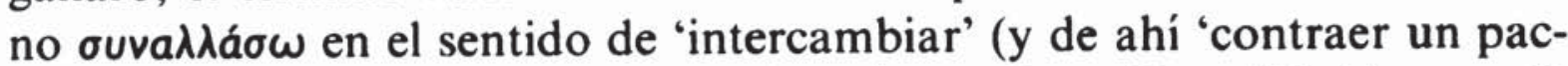
to', 'entrar en negocios') está atestiguado en Leg. Gort. IX 44, etc.; P. Cairo Zenon 359, 6, 12 (III a. C.); Arist., Et. Nic. 1162 b 24, etc.; SIG 742, 55 (Éfeso, I a. C.). Cf. L. Dubois (IGDS, p. 133), quien ve en este término, no atestiguado en ningún otro lugar con el mismo sufijo, el

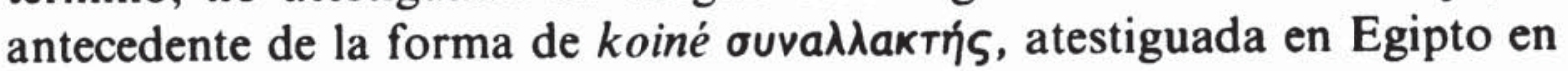

${ }^{53}$ Cf. M. B. Hatzopoulos, Actes de vente, p. 22, que interpreta el aútós que

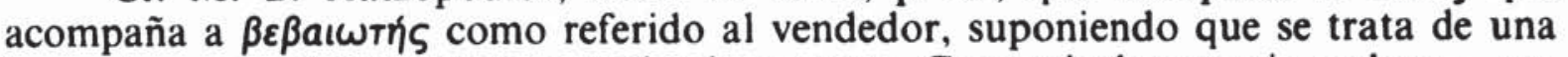
herencia, y que el propietario anterior ha muerto. Gramaticalmente sin embargo, parece más probable que se refiera al sujeto, es decir al comprador (lo que no tiene mucho sentido), o a la última persona mencionada, es decir, al vecino. Dados los testimonios de la función de los vecinos como garantes o testigos me parece esta posibilidad la más plausible.

${ }^{34}$ F. Cordano, $B A 69,1984$, p. 37. Cf. F. Sartori, Athenaeum 32, 1954, pp. 356-83.

$5 s$ C. Ampolo, PP 40, 1985, p. 364, nota 11.

s6 G. Manganaro, $P P$ 44, 1989, pp. 192-3. 


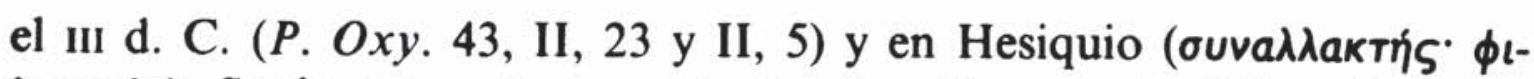

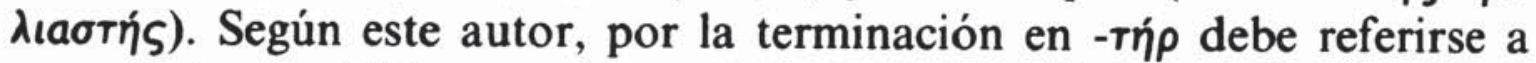
un colegio presidido por el пробтáras y encargado de vigilar la legalidad en las transacciones entre particulares. Con este colegio pone en relación las abreviaturas $\Delta \Phi$ que aparecen en la inscripción núm. 1 (lín.

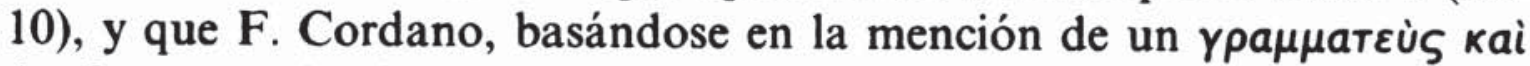
фрабати́p en dos inscripciones de Acras (IG XIV 212), y en el sentido

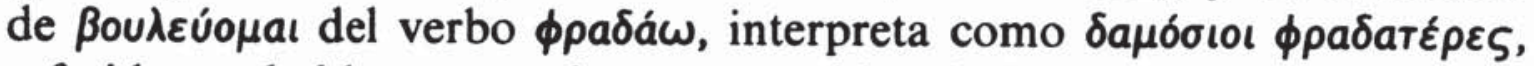
referido probablemente a los responsables de la transacción y quizá a los depositarios ${ }^{57}$. G. Manganaro interpreta estas abreviaturas como numerales (506) que indicarían el número de inventario del archivo en que estaría depositado el documento original, bajo la vigilancia del

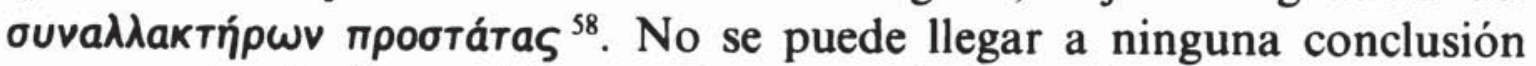
segura sobre la figura del пробта́таৎ ante la falta de paralelos, pues en ninguno de los contratos de venta conocidos de otras zonas del mundo griego se menciona ni un árbitro de los contratantes, ni un encargado de su vigilancia. Sin embargo, tanto las menciones en algunos de los öpo áticos de contratos originales ${ }^{59}$, como la existencia de archivos como el de Macedonia (al que corresponde B) o el de Tenos (al que corresponde $\mathrm{C}$ ), demuestran que la práctica de depositar el contrato original en un sitio público o en manos de terceros debía ser bastante normal. El hecho de que en el reverso del plomo núm. 2 de Camarina esté inscrito un nombre propio en genitivo hace pensar que también aquí se menciona el nombre del depositario ${ }^{60}$.

\section{III}

Por los testimonios epigráficos conservados parece que el contrato de venta es un tipo de transacción muy formalizado, al menos a partir del s. Iv, con unos elementos fijos que, aunque con pequeñas variantes de expresión, normalmente dependiendo de zonas, parecen coincidir en todos los contratos conservados. Aunque no se trata de un contrato de venta, he incluido en el apéndice un documento en plomo de Pech

57 F. Cordano, $B A 69,1984$, p. 39.

58 G. Manganaro, $P P 44,1989$, pp. 192-3.

59 Cf. nota 46.

${ }^{60}$ Cf. C. Ampolo, PP 40, 1985, p. 364. Cf. F. Cordano (BA 69, 1984, pp. 42-3), para quien el nombre es el del comprador, y el hecho de que estuviera en el reverso de la laminilla plegada indica que se encontraba en un archivo, no necesariamente público. 
Maho (A) que informa sobre una venta de barcas, y que tiene el interés de ser el testimonio epigráfico más antiguo conservado de este tipo de transacción, y de atestiguar el uso de fianzas cuando el pago no se realizaba de una vez. Es posible que la transacción no se realizara mediante ningún contrato escrito, pero la terminología empleada revela ya en esta época el empleo de un vocabulario técnico, sobre todo en la dis-

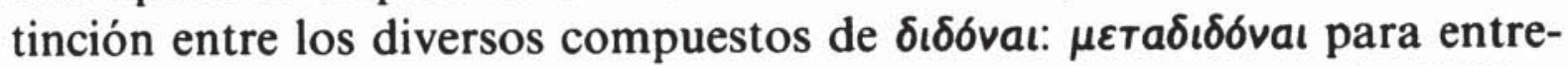

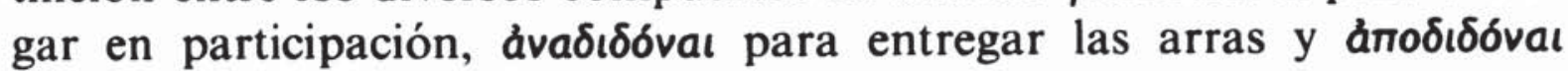

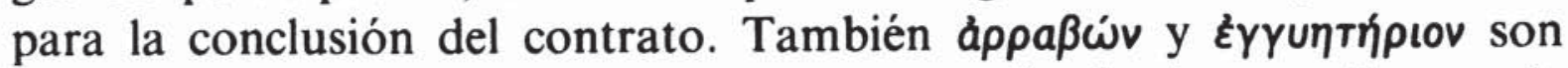
términos técnicos que implican un uso generalizado de estas formas de garantía ${ }^{61}$. Tampoco faltan los testigos, de los que se mencionan dos listas, una para cada momento del pago. Otro tipo de documentos que he incluido en el apéndice, aunque tampoco representan el contrato original de venta, son los öpoı. La mención en alguno de ellos del contrato original, y el hecho de que sean mucho más concisos y escuetos en información que los otros documentos conservados, demuestra que su función era la de información pública del estado temporal de una propiedad, cuya transacción real se había realizado en un contrato depositado en algún archivo. Ya hemos visto que algunos de los otros contratos analizados parecen indicar la existencia de una copia o del texto original en manos de un depositario. F. Pringsheim establece una evolución desde el uso indispensable de los testigos en las transacciones al del documento escrito, producida durante el s. Iv a. C. Según este autor, el hecho de que hasta el 316-5 a. C. ningún zpos contenga nombre del depositario, y de que las referencias a contratos escritos en la literatura jurídica empiecen a aparecer en la segunda mitad del s. Iv, hace pensar que sólo a partir de entonces el uso del documento escrito se hizo frecuente. En esta época ambos elementos, testigos y documento escrito, se combinarían, y hacia el 330 el segundo solo sería suficiente ${ }^{62}$. Sin embargo, las referencias literarias no pueden utilizarse como referencia decisiva ya que no tenemos muchos discursos jurídicos anteriores al siglo Iv, y, por otra parte, el carácter unitario de los contratos analizados, aun procediendo de zonas tan diversas, la existencia de elementos como archivos u otro tipo de depositarios de contratos y el tecnicismo que refleja ya la inscripción de Pech Maho, aunque no sea el contrato propiamente dicho, hacen pensar que la práctica del contrato

${ }^{61}$ M. Lejeune y J. Pouilloux, CRAI, 1988, p. 534. Sobre el uso de las arras en la compra-venta griega v. M. Talamanca, op. cit. en nota 9, pp. 3-19.

$62 \mathrm{~F}$. Pringsheim, "The transition from witnessed to written transactions in Athens", Festg. Simonius, 1955, pp. 287-97 (= Gesammelte Abhandlungen, II, Heidelberg 1961, pp. 401-9). 
escrito es una costumbre que en el s. IV a. C. ya tiene una tradición. Una de las razones que da F. Pringsheim para apoyar su teoría de la evolución del contrato con testigos al escrito, la de que a partir del 350 a. C. los testigos son sustituidos por el contrato escrito en las referencias literarias, no está apoyada por los documentos epigráficos. En los contratos analizados los testigos siguen apareciendo junto a los garantes no sólo en todo el s. IV, sino también en el s. III (C, M, N), y probablemente en el II (núm. 7 de Morgantina, donde los ă $\mu$ nохо seguramente cumplen las funciones de testigos y garantes).

La existencia de garantes en la mayor parte de los contratos analizados demuestra que el vendedor no bastaba como garante de sí mismo todavía en la ley de venta de los siglos III-II a. C., al menos en la mayor parte de Grecia, si bien en Atenas este elemento había caído en desuso al parecer ${ }^{63}$.

Las diferencias formales entre contrato de venta y пра̃ podrían deberse a una institución más fija y general del primero frente a un uso poco frecuente del segundo. Pero creo que más bien se deben a las diferencias entre el carácter tan sencillo de la simple venta - sobre todo si se acepta el concepto único de venta al contado- y la complejidad de la $\pi \rho \tilde{a} \sigma \iota \varsigma$ éni $\lambda u ́ \sigma \varepsilon \iota$ que tiene que adaptarse a muy diversas situaciones según las causas que la originen, y a distintas condiciones como

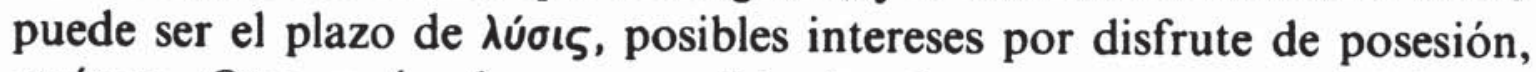

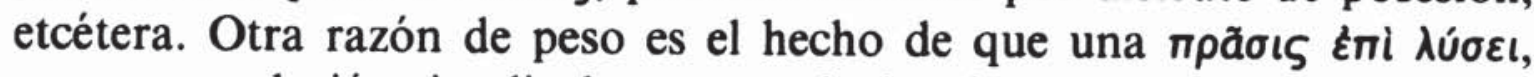
con su conclusión, implicaba un estado igual al de antes de efectuarse el contrato, por lo que no sólo podía destruirse el documento sino que en muchos casos su destrucción sería la forma de dar por concluido el asunto. Por el contrario, una transacción de venta supone un cambio ilimitado de propiedad, cuyo certificado es no sólo importante contra reclamaciones de terceros, sino también en caso de futuras transacciones respecto al mismo objeto.

Los contratos de venta, aparentemente tan simples y con una estructura formular tan claramente definida presentan, sin embargo, una serie de problemas que tendrán que esperar a nuevos hallazgos que aporten nuevos datos para poderse resolver. No puede explicarse de forma definitiva la existencia de la garantía por cantidades fijas, atestiguada en algunos contratos del registro de Tenos, ni la ausencia de testigos y garantes en el contrato de Amorgos, ni por qué unas veces aparecen sólo testigos y otras testigos y garantes, incluso en una misma ciudad como ocurre en Anfipolis, ni tampoco las diferencias de precio, y su falta de

${ }^{63}$ Cf. T. W. Beasley, Le Cautionnement dans le Droit Grec, Roma 1978, p. 33 s. 
relación, al menos aparente, en muchos casos con el valor real del objeto de compra en algunos de los contratos. Es posible que en muchos casos estemos ante transacciones bastante más complejas, cuyo conocimiento quizá modifique en algunos detalles la interpretación hoy día aceptada de la ley de venta griega.

\section{APÉNDICE}

Contratos de venta sicilianos:

1. Camarina. Lámina de plomo con un contrato de venta de tierra; s. IV-III a. C.; P. Pelagatti, Kokalos 18-9, 1972-73, p. 163; R. Martin, Kokalos 18-19, 1976, p. 122 ss.; F. Cordano, "Camarina VII», BA 69, 1984, p. 31 ss.; C. Ampolo, «Il nuovo contratto di Camarina», PP 40, 1985 , p. 361 ss.; G. Manganaro, "Casa e terra a Kamarina», PP 44, 1989, p. 192 ss.; L. Dubois, IGDS, Roma 1989, pp. 131-5, núm. 124; SEG XXXIX (1989) 998.

2. Camarina. Lámina de plomo con una lista de nombres que seguramente corresponden a los garantes de un contrato contenido en la parte no conservada del texto; s. IV-III a. C.; F. Cordano, "Camarina VII", $B A$ 69, 1984, p. 41 ss.; G. Manganaro, "Casa e terra a Kamarina», $P P 44$, 1989, pp. 194-195; L. Dubois, IGDS, Roma 1989, pp. 1356, núm. 125; SEG XXXIX (1989) 999.

3. Camarina. Lámina de plomo con un contrato de venta de tierra; s. II a. C. (?); G. Manganaro, "Tavolette di piombo", ASNP 7, 1977, p. 1339; SEG XXVII (1977) 650; Bull. Epigr., 1979, 676; «Casa e terra a Kamarina», $P P 44,1989$, pp. 190-191; L. Dubois, IGDS, Roma 1989, pp. 136-39, núm. 126; SEG XXXIX (1989) 996.

4. Camarina. Lámina de plomo con un contrato de venta de tierra; s. II a. C. (?); G. Manganaro, "Tavolette di piombo", ASNP 7, 1977, p. 1339; $S E G$ XXVII (1977) 651; "Casa e terra a Kamarina», $P P$ 44, 1989, p. 191; SEG XXXIX (1989) 997.

5. Camarina. Lámina de plomo con un contrato de venta de tierra; s. III-II a. C.; G. Manganaro, "Testi e Monumenti», PP 44, 1989, pp. 196-9 (Kam. VI); SEG XXXIX (1989) 1001.

6. Camarina. Lámina de plomo con un contrato de venta de una casa; s. III-II a. C.; G. Manganaro, "Testi e Monumenti», PP 44, 1989, p. 199 s. (Kam. VII); SEG XXXIX (1989) 1002.

7. Morgantina (Serra Orlando junto a Aidone). Laminilla de pla-

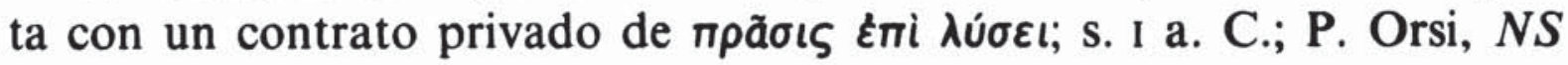


serie 5 IX, 1912, pp. 452-454; D. Comparetti, «Laminetta argentea iscritta di Aidone», ARSAA 1, 1914, pp. 113-118; SEG IV (1919) 62; V. Arangio Ruiz y A. Olivieri, Inscriptiones Graecae Siciliae et infimae Italiae ad ius pertinentes, Nápoles 1925, pp. 139-142; K. Latte, Gnomon 3, 1927, p. 371; G. De Sanctis, "Miscellanea. Pagamento degli Epidauri» RFC 56, 1928, pp. 525-526; J. V. A. Fine, Horoi, Hesperia, Suppl. IX, 1951, p. 166 (las tres primeras líneas); G. Manganaro, "Tavolette di piombo inscritte della Sicilia Greca», ASNP 7, 1977, pp. 1342-1344; L. Dubois, IGDS, Roma 1989, pp. 231-3, núm. 194.

8. Morgantina. Lámina de plomo con un contrato de venta de tierra; s. III-II a. C.; G. Manganaro, "Testi e Monumenti», PP 44, 1989, pp. 203-5 (Morg. I); SEG XXXIX (1989) 1008.

9. Morgantina. Lámina de plomo con un contrato de venta de una casa; s. III-II a. C.; G. Manganaro, "Testi e Monumenti», PP 44, 1989, pp. 205-7 (Morg. III); SEG XXXIX (1989) 1009.

10. Morgantina. Lámina de plomo con un contrato de venta de una casa; s. III-II a. C.; G. Manganaro, "Testi e Monumenti», PP 44, 1989, pp. 209-11 (Morg. V); SEG XXXIX (1989) 1011.

Selección de contratos de venta de otros lugares del mundo griego:

A. Ресн Maho. Informe sobre la venta de unas barcas; s. v a. C.; M. Lejeune y J. Pouilloux, CRAI, 1988, pp. 225-232; M. Lejeune, REG 104, 1991, pp. 311-29.

B. TENOS. Ejemplo núm. 36 del registro; contrato de venta de una casa con terreno; s. III a. C.; R. Dareste, Recueil, pp. 80-2; IG XII 5, 872; SIG 1201.

C. Ematia (Macedonia). Ejemplo núm. 1 del registro; contrato de

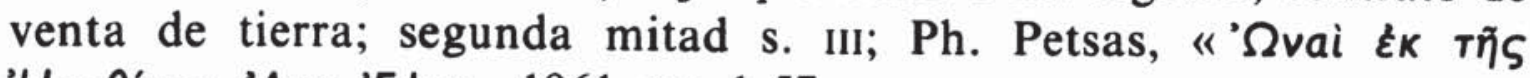

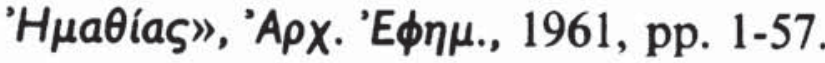

D. Torone. Venta de una casa; primera mitad s. IV a. C.; M. Ka-

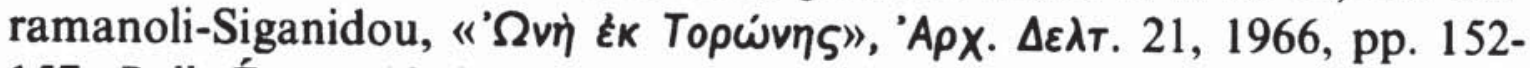
157; Bull. Épigr., 1968, 328.

E. Olinto. Venta de una casa; primera mitad s. IV a. C.; D. M. Robinson, TAPA 59, 1928, pp. 225-232.

F. Olinto. Venta de una casa; primera mitad s. IV a. C.; D. M. Robinson, TAPA 62, 1931, p. 49 ss.

G. Olinto. Venta de una casa; mediados s. IV a. C.; D. M. Robinson, $T A P A 65,1934$, pp. 124-127.

H. Olinto. Venta de una casa; s. IV a. C.; D. M. Robinson, TAPA 65,1934 , pp. 127-129. 
I. Kellion. Venta de una casa; mediados s. IV a. C.; M. B. Hatzopoulos, Actes de vente, pp. 19-23, núm. 1, lám. VIII.

J. Kellion. Venta de viñas y casas; mediados s. IV a. C.; M. B. Hatzopoulos, Actes de vente, pp. 23-7, núm. 2, láms. IX-X.

K. Kellion. Venta de una casa; mediados s. IV a. C.; M. B. Hatzopoulos, Actes de vente, pp. 31-3, núm. 4, lám. XIII.

L. Smixi. Venta de unas tierras; mediados s. IV a. C.; M. B. Hatzopoulos, Actes de vente, pp. 34-40, núm. 6, láms. XV-XIX.

M. Anfípolis. Venta de una casa con su terreno; mediados del s.

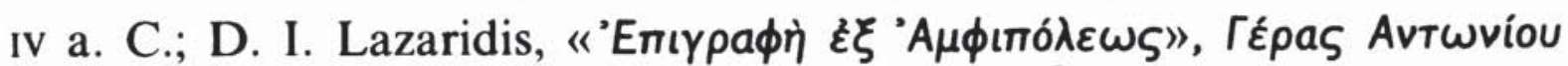

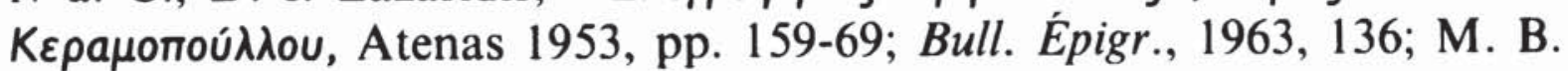
Hatzopoulos, Amphipolis, pp. 38-43, núm. 7.

N. Anfípolis. Venta de una casa; mediados del s. III a. C.; D. I. Lazaridis, $B C H$ 85, 1961, pp. 429-431; Bull. Épigr., 1963, 136; SEG XXIV (1969) 584; M. B. Hatzopoulos, Amphipolis, pp. 52-4, núm. 12.

$\tilde{\mathrm{N}}$. Anfípolis. Venta de un viñedo; primera mitad s. IV a. C.; D. I. Lazaridis, BCH 85, 1961, pp. 431-434; Bull. Épigr., 1969, 372; M. B. Hatzopoulos, Amphipolis, pp. 33-8, núm. $6^{64}$.

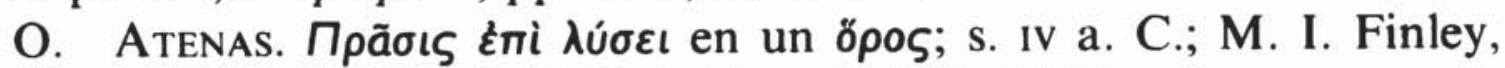
Horos-Inscriptions, App. I, núm. 15 (= IG II 2, 2687).

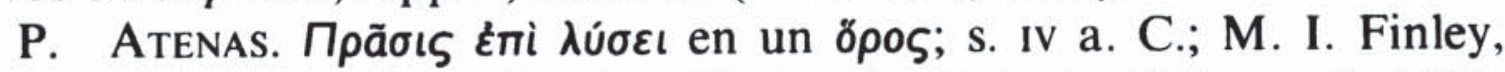
Horos-Inscriptions, App. I, núm. 17 (= L. Robert, Helenica 8, 1935, 223, núm. 3).

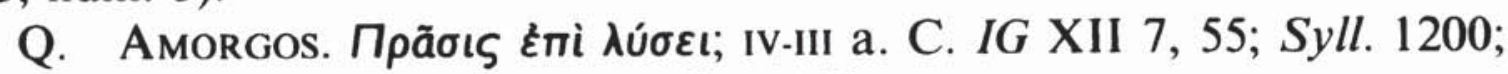
M. I. Finley, Horos-Inscriptions, núm. 102.

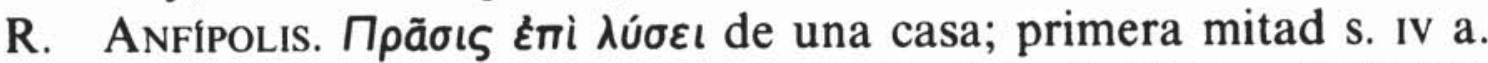
C.; D. I. Lazaridis, $B C H 85,1961$, pp. 426-429; C. Vatin, $B C H 86$, 1962, pp. 524-534; Bull. Épigr., 1963, 136; SEG XXIV (1969) 583; M. B. Hatzopoulos, Amphipolis, pp. 14-9, núm. 1.

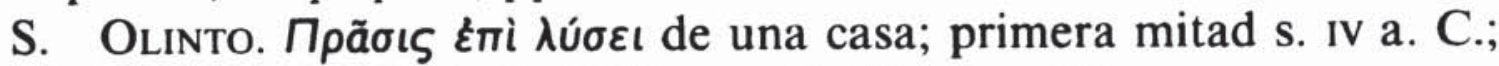
D. M. Robinson, TAPA 62, 1931, pp. 43-49, núm. $2^{65}$.

\section{María Paz de Hoz}

${ }^{64}$ Para otros contratos de venta procedentes de la peninsula Calcidica v. M. B. Hatzopoulos, Actes de vente; D. Hennig, «Kaufverträge über Häuser und Ländereien aus der Chalkidike und Amphipolis» Chiron 17, 1987, pp. 143-169, en los que se encontrará más bibliografia.

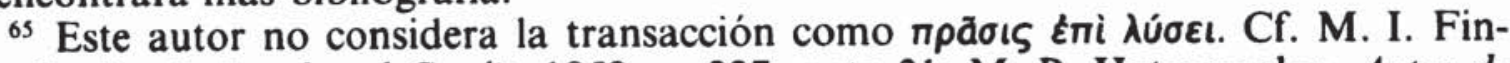
ley, Studies in Land and Credit, 1952, p. 227, nota 21; M. B. Hatzopoulos, Actes de vente, p. $61 \mathrm{~s}$. 